\title{
Electrospun Asymmetric Membranes as Promising Wound Dressings: A Review
}

\author{
Mariana F. P. Graça ${ }^{1}$, Duarte de Melo-Diogo ${ }^{1}$, Ilídio J. Correia ${ }^{1,2, * \mathbb{D}}$ and André F. Moreira ${ }^{1, *(D)}$ \\ 1 CICS-UBI—Centro de Investigação em Ciências da Saúde, Universidade da Beira Interior, Av. Infante D. Henrique, \\ 6200-506 Covilha, Portugal; mariana.graca@ubi.pt (M.F.P.G.); demelodiogo@fcsaude.ubi.pt (D.d.M.-D.) \\ 2 CIEPQPF-Departamento de Engenharia Química, Universidade de Coimbra, Rua Silvio Lima, \\ 3030-790 Coimbra, Portugal \\ * Correspondence: icorreia@ubi.pt (I.J.C.); afmoreira@fcsaude.ubi.pt (A.F.M.); Tel.: +351-275-329-055 (I.J.C.); \\ Fax: +351-275-329-099 (I.J.C.)
}

Citation: Graça, M.F.P.; de Melo-Diogo, D.; Correia, I.J.; Moreira, A.F. Electrospun Asymmetric Membranes as Promising Wound Dressings: A Review. Pharmaceutics 2021, 13, 183. https://doi.org/ 10.3390/pharmaceutics13020183

Academic Editor: Teresa Cerchiara Received: 15 December 2020

Accepted: 21 January 2021

Published: 30 January 2021

Publisher's Note: MDPI stays neutral with regard to jurisdictional claims in published maps and institutional affiliations.

Copyright: (C) 2021 by the authors. Licensee MDPI, Basel, Switzerland. This article is an open access article distributed under the terms and conditions of the Creative Commons Attribution (CC BY) license (https:/ / creativecommons.org/licenses/by/ $4.0 /)$.

\begin{abstract}
Despite all the efforts that have been done up to now, the currently available wound dressings are still unable to fully re-establish all the structural and functional properties of the native skin. To overcome this situation, researchers from the tissue engineering area have been developing new wound dressings (hydrogels, films, sponges, membranes) aiming to mimic all the features of native skin. Among them, asymmetric membranes emerged as a promising solution since they reproduce both epidermal and dermal skin layers. Wet or dry/wet phase inversion, $\mathrm{scCO}_{2}$-assisted phase inversion, and electrospinning have been the most used techniques to produce such a type of membranes. Among them, the electrospinning technique, due to its versatility, allows the development of multifunctional dressings, using natural and/or synthetic polymers, which resemble the extracellular matrix of native skin as well as address the specific requirements of each skin layer. Moreover, various therapeutic or antimicrobial agents have been loaded within nanofibers to further improve the wound healing performance of these membranes. This review article provides an overview of the application of asymmetric electrospun membranes as wound dressings displaying antibacterial activity and as delivery systems of biomolecules that act as wound healing enhancers.
\end{abstract}

Keywords: asymmetric membranes; bioactive molecules; electrospun membranes; skin regeneration; wound dressing

\section{Introduction}

Skin is the largest and outermost organ of the human body, with approximately $2 \mathrm{~m}^{2}$ of area and a mean thickness of $2.5 \mathrm{~mm} \mathrm{[1,2].} \mathrm{This} \mathrm{organ} \mathrm{is} \mathrm{involved} \mathrm{in} \mathrm{important}$ functions in the human body, namely thermoregulation, prevention of water and fluid loss, immune surveillance, hormone synthesis, and sensory detection [1,3]. In addition, due to its anatomical location, it also acts as a barrier against microbial invasion as well as mechanical and chemical insults, thus conferring protection to the body [3]. In this way, when the skin's structure is compromised, the use of dressing materials to cover and protect the wound to re-establish a temporary or, in the case of extensive wounds, a permanent fully functional body barrier is of utmost importance [4].

In this field, various biomedical alternatives have been developed and applied over the years to assist the wound healing process. The skin grafts (autografts, allografts, xenografts) remain as the most conventional and widely used therapeutic approach for restoring the skin's structure after an extensive lesion [5]. Despite their intrinsic advantages, autografts present limited availability and induce additional morbidity to the patient; while alo- and xenografts can lead to immune rejection [6,7]. In turn, wound dressings, i.e., 3dimensional materials/structures that can be applied in the wound site either temporarily or permanently, act as a barrier against microorganisms, external insults, and dehydration, while simultaneously accelerating the wound healing [3,8]. Today, some wound dressings 
are already applied in the clinic, for example, Duoderm ${ }^{\circledR}$ [9], Acticoat ${ }^{\mathrm{TM}}$ [10], Aquacel $\mathrm{Ag}^{\circledR}$ [11], DermFactor ${ }^{\circledR}$ [12], and Procellera ${ }^{\circledR}$ [13]. Despite the advantages presented by these commercial wound dressings, they still present drawbacks such as adhesion to the surface of the lesion, which may cause additional damage upon periodic replacement, and the cost [8].

To address these limitations, tissue engineering researchers have been focusing on the development of new different biomimetic wound dressings. Films, hydrogels, and hydrocolloids are some examples, and they present a few advantages such as the capacity to enable the transmission of gases and maintain a moist environment at the wound site, which improves and accelerates the wound healing process [14]. However, these approaches also have some limitations, the possibility of maceration, and the necessity for periodic replacement, and until now, none of them have been capable of fully restoring the skin's native structure and functions $[15,16]$. Such emphasizes the need for the development of an efficient wound dressing that can provide the ideal structural and biochemical mechanisms for promoting efficient skin regeneration. Asymmetric membranes, widely explored for filtration and gas separation, recently captured the attention of researchers for being applied as wound dressings [17-19]. The utilization of asymmetric wound dressings aims to reproduce a skin-like layered organization, which consists in a top layer to protect the wound site and mechanical support, and a bottom layer that facilitates cell migration, adhesion, and proliferation, and provides a moist environment [20]. Particularly, the nanofibrous composition of asymmetric electrospun membranes allows them to reproduce the extracellular matrix (ECM) structure, thus providing additional anchoring points for cell adhesion and proliferation [21].

In this review, the most common production techniques and key properties of asymmetric membranes were overviewed, focusing on the development of asymmetric electrospun membranes aimed for skin regeneration. Furthermore, the application of asymmetric electrospun membranes to mediate the delivery of biologically active molecules, i.e., antibacterial agents or wound healing enhancers, was also highlighted.

\section{Asymmetric Membranes}

Asymmetric membranes are 3D matrices composed of two layers, which enable a high similarity with the native skin while protecting the wound against bacterial penetration, dehydration, and exudate accumulation. These membranes have been emerging as ideal wound dressings due to their inherent capacity to mimic both epidermal and dermal skin layers [22,23]. In the literature, it is often reported that an ideal wound dressing must act as a protecting barrier, which avoids microorganisms' invasion as well as additional damages resulting from external hazard agents $[3,24,25]$. Further, these dressings should also promote cell proliferation and migration, angiogenesis, sustain a moist environment at the wound site, and be compatible with gaseous' and fluids' exchanges [25]. Additionally, the wound dressing must be produced with biocompatible and biodegradable materials, be cost-effective, and its production scalable [3]. In this regard, the structural features of the asymmetric membranes fulfil the requirements for their application as dressings in the healing process (as represented in Figure 1). The external (i.e., top) layer of the asymmetric membranes often presents a dense matrix with low total porosity, small pores (i.e., inferior to the bacteria's size), and a hydrophobic character [26]. Such characteristics provide to the wound site both protection against external agents (e.g., bacteria, radiation) and mechanical stability without compromising the gaseous exchanges, likewise the epidermis layer [27]. In turn, the internal (i.e., bottom) layer is composed of hydrophilic materials and a loose structure with high porosity and large pores [28]. Therefore, this layer facilitates cell migration, adhesion, and proliferation, the absorption of wound exudate, as well as providing a moist environment compatible with nutrient exchange [20].

So far, the production of asymmetric membranes has been accomplished by wet or dry / wet phase inversion, $\mathrm{scCO}_{2}$-assisted phase inversion, and electrospinning methodologies [29]. 


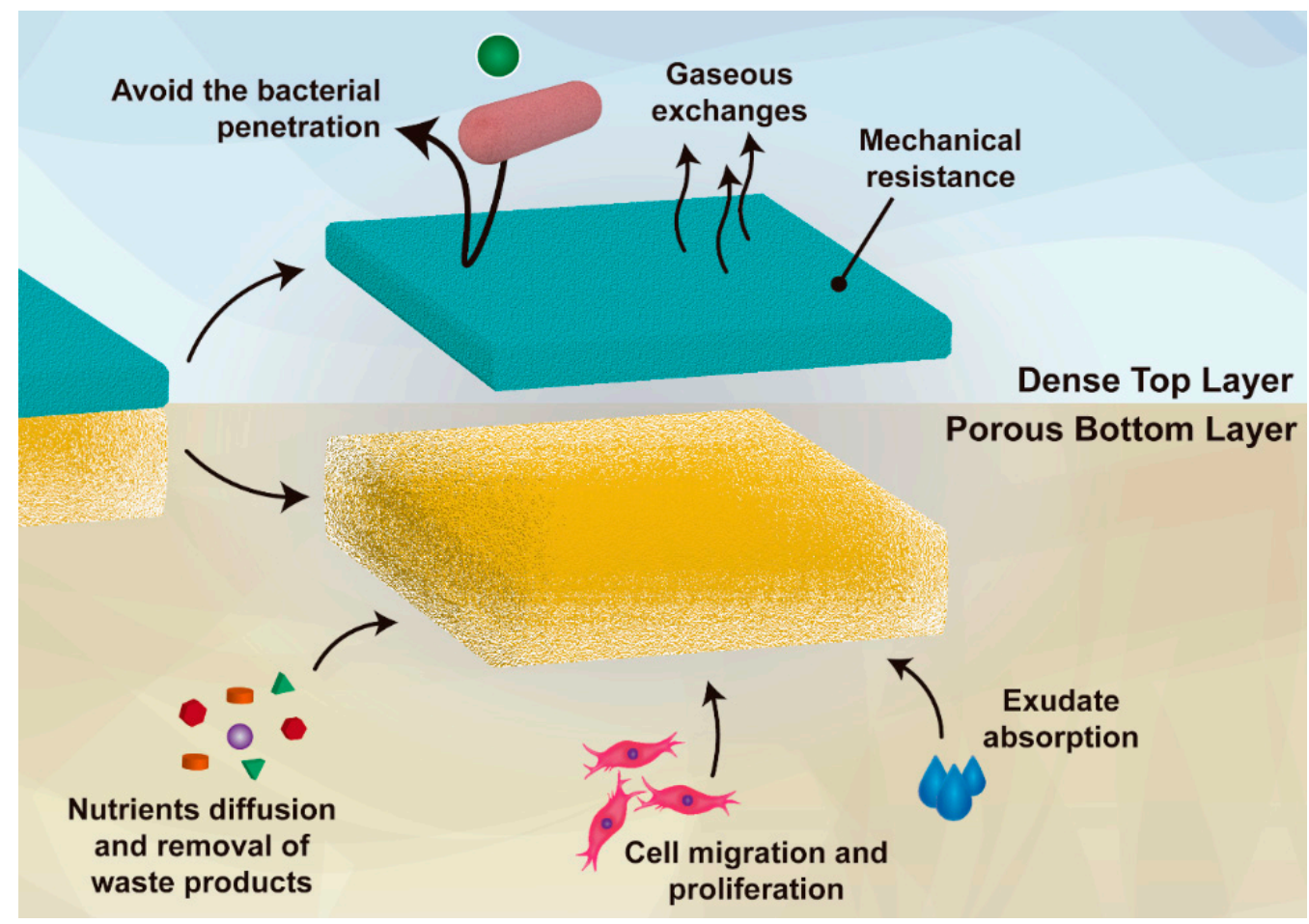

Figure 1. Illustration of the main functions of both layers (top and bottom) of an asymmetric membrane.

In fact, the wet-phase inversion method was the first technique used to produce membranes with an asymmetric structure [30]. This technique takes advantage of the polymer precipitation in a non-solvent coagulant bath to originate a membrane comprising a compact top layer and a porous sub-layer [31]. Marcano and colleagues reported the development of poly(hydroxyalkanoate)/poly(vinyl pyrrolidone) (PVP) asymmetric membranes using ultrapure water $\left(0.05501 \mu \mathrm{S} \times \mathrm{cm}^{-1}\right.$ and $\left.18.18 \mathrm{M} \Omega \times \mathrm{cm}\right)$ as a coagulation bath [32]. For this purpose, these authors dissolved both polymers in $\mathrm{N}$-methyl-2-pyrrolidone, casted onto a glass plate in a $140 \mu \mathrm{m}$-thick layer and submersed it in the aqueous coagulation bath for $1 \mathrm{~h}$ at room temperature. Furthermore, Marcano and colleagues also reported that increasing concentrations of PVP (porogen polymer), from 0 to 10 and $30 \%$, led to asymmetric membranes with a greater surface pore number, pore size, and pore density. A higher porosity also resulted in an enhanced capacity to encapsulate a protein-based therapeutic (Dispersin B), reaching the maximum of $\approx 12 \mu \mathrm{g} \times \mathrm{cm}^{-2}$ at $30 \%$ of PVP. Additionally, these authors also demonstrated that the polyhydroxyalkanoate/PVP (30\%) asymmetric membrane inhibited the formation of biofilm by Staphylococcus epidermidis (S. epidermis) in $33 \%$ and mediated the detachment of $26 \%$ of the formed biofilm [32].

Nevertheless, the asymmetric membranes produced through the wet-phase inversion method present some limitations that hinder their efficacy in promoting the wound healing process, such as a defective and thin top layer that fails in preventing excessive water evaporation and protection against external agents. To address these issues, an evaporation step was added before the polymer immersion in the coagulant bath, originating the dry/wet-phase inversion method [33]. This approach requires the utilization of a volatile solvent that is partially evaporated, which increases the polymer concentration at the top of the film resulting in a denser and less porous top layer [31]. Mi et al. prepared a chitosan (CS) asymmetric membrane enriched with silver sulfadiazine through the dry/wet-phase inversion technique [34]. In this approach, CS was dissolved in an aqueous acetic acid solution ( $1 \mathrm{wt} . \%)$, cast into a mold, incubated at $50{ }^{\circ} \mathrm{C}$ for 10 to $60 \mathrm{~min}$, and immersed in the coagulant solution $\left(\mathrm{NaOH}(2 \mathrm{wt} . \%)-\mathrm{Na}_{2} \mathrm{CO}_{3}(0.05 \mathrm{wt} . \%)\right)$ for $24 \mathrm{~h}$. The authors observed an increase in the thickness of the dense top layer and an overall decrease in the porosity of the asymmetric membranes when longer evaporation times were performed. Moreover, 
such structural alterations resulted in a decrease in the water uptake capacity (900 to 132\%) and in the water vapor transmission rate (2800 to $2110 \mathrm{~g} \times \mathrm{m}^{-2} \times$ day $\left.^{-1}\right)$ [34].

Alternatively, the $\mathrm{scCO}_{2}$-assisted phase inversion technique, as a green technology, has also been employed for the production of asymmetric membranes [29]. In this approach, the membrane assembly occurs via the precipitation of a polymeric solution in $\mathrm{CO}_{2}$ supercritical conditions [35]. Therefore, the asymmetric membrane properties can be optimized by adjusting the concentration of the casting solution, the ratio of non-solvent/solvent, the pressure, the temperature, and the depressurization rate. As the main advantage, this technique allows the replacement of conventionally used organic solvents by $\mathrm{scCO}_{2}$, which is environmentally friendly and can enhance the biocompatibility of the produced wound dressings [36]. Morgado and co-workers developed a poly(vinyl alcohol) (PVA)/CS asymmetric membrane loaded with ibuprofen via the $\mathrm{scCO}_{2}$-assisted phase inversion technique, aiming to apply it as a wound dressing [37]. With that in mind, the authors prepared a PVA/CS solution (17.25 wt.\%) containing $\beta$-cyclodextrins loaded with ibuprofen. Then, the solution was cast into a stainless-steel cap and performed the supercritical immersion precipitation technique $\left(90 \% \mathrm{CO}_{2}\right.$ and $10 \%$ ethanol, flow of $5 \mathrm{~mL} \times \mathrm{min}^{-1}$ for $120 \mathrm{~min}$, $20 \mathrm{MPa}$, and $45^{\circ} \mathrm{C}$ ) testing two different depressurization rates (4 and $10 \mathrm{~min}$ ). The authors reported that both depressurization rates resulted in membranes with similar overall porosity (average pore diameter $\approx 0.7 \mu \mathrm{m}$ and porosity $37 \%$ ), being obtained smaller and more homogeneous pores at $10 \mathrm{~min}$ of depressurization. Further, the increase in the depressurization rate from 4 to $10 \mathrm{~min}$ also resulted in asymmetric membranes with a denser top layer. Moreover, the asymmetric membranes PVA/CS+ $\beta$-cyclodextrins loaded with ibuprofen (10 min of depressurization) presented a swelling of $200 \%$ and $310 \%$ at $\mathrm{pH} 8$ and 5 , respectively, and a water vapor transmission rate of $410 \mathrm{~g} \times \mathrm{m}^{-2} \times$ day $^{-1}$. In the in vivo studies, the group treated with the asymmetric membranes PVA $/ C S+\beta$-cyclodextrins loaded with ibuprofen (10 min of depressurization) presented, after 21 days, a higher wound closure than the control, i.e., the wounded area was 2-times inferior and minimized both the scab formation and inflammatory response [37]. However, the development of asymmetric membranes by the $\mathrm{scCO}_{2}$-assisted phase inversion technique requires the use of specialized, robust, and costly high-pressure apparatus for achieving the supercritical conditions, which hinders the scalability of the production process, and the translation to the clinic [29].

\subsection{Electrospinning Technique}

The electrospinning apparatus usually used to produce nanofiber-based structures comprises four different components: A syringe pump, a capillary needle, a high voltage power supply, and a metal collector (Figure 2) [38]. During the electrospinning process, an electric field is applied between the needle and the collector [39]. At a critical voltage, the polymeric solution is ejected from the tip of the Taylor cone towards the metal collector. Such promotes the solvent evaporation and the deposition of polymeric fibers in the collector [40]. The properties of the produced polymeric structures are controlled by the feeding solution (e.g., concentration, viscosity, surface tension, solvent volatility, and conductivity), environmental conditions (e.g., temperature and humidity), and operating parameters (e.g., voltage, solution flow rate, and needle-to-collector distance) [41]. Such will directly impact on the fibers' diameter (usually at nanoscale) and arrangement, mechanical strength, and structural porosity [42,43]. Further, the possibility to select different types of tips (e.g., co-axial, multi-jet, and multifluidic co-axial) and collectors (e.g., plain or grid-like structure as well as stationary or rotating) influences the fibers topography and spatial arrangement [39]. Moreover, the electrospinning technique can also be optimized to be compatible with the cell encapsulation enhancing the wound healing capacity, contrasting with the other techniques explored for producing asymmetric polymeric membranes [44-47]. For example, Alfare De Prá et al. observed that the deposition of poly(caprolactone) (PCL) fibers in a stationary cylinder resulted in randomly oriented fibers with an average diameter of $1142 \pm 391 \mathrm{~nm}$ [48]. Otherwise, when the electrospinning 
process was performed with the cylinder collector at a rotation speed of $2000 \mathrm{rpm}$, the mean fiber diameter decreased to $663 \pm 334 \mathrm{~nm}$ and presented a more homogeneous size distribution and fiber orientation. In wound healing applications, the fibers present in the electrospun membranes are aimed to mimic the interconnected 3D network of extracellular matrix of native skin [49]. Additionally, the high surface area-to-volume ratio characteristic of electrospun membranes facilitates the cell adhesion and proliferation [50].

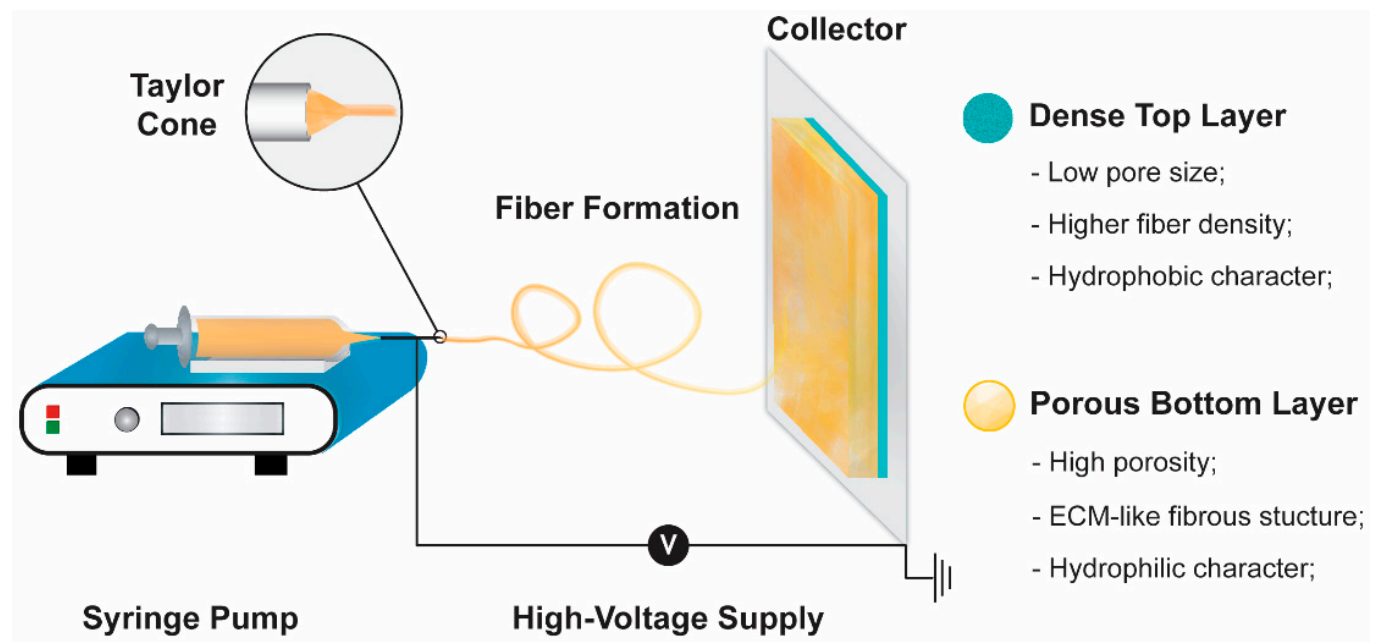

Figure 2. Illustration of a conventional electrospinning apparatus used in the production of an asymmetric electrospun membrane. The physical properties of each layer of the produced membrane are also presented.

The electrospinning technique presents the advantage of being compatible with natural, semi-synthetic, or synthetic polymers, which facilitates the development of multifunctional dressings [51]. In this way, the polymers' selection for wound healing applications must be based on their biocompatibility, biodegradability, hydrophilicity, and mechanical properties [51,52].

The natural polymers are recognized by their superior biocompatibility and possible interaction with cells via cell surface adhesion receptors which enable the support of cell adhesion and proliferation [24]. One reason for this feature is its similarity with some macromolecules found in the human body or its presence in the ECM [51]. CS [26], hyaluronic acid (HA) [28], collagen [53], gelatin (Gel) [54], and silk [20] are some examples of natural polymers usually employed to produce nanofibrous mats. However, natural polymers are usually associated with sub-optimal mechanical strength, faster degradation profiles, and higher costs [52]. On the other hand, synthetic polymers are widely used due to their good mechanical properties (like elasticity and stiffness) and tunable biodegradability. Moreover, the synthesis of these polymers can be scaled up, lowering the costs [52]. Some examples of synthetic polymers used in the electrospinning technique are PCL [55], PVA [49], poly(lactide-co-glycolide) (PLGA) [56], and poly(L,D-lactic acid) (PLA) [57]. Otherwise, these polymers also have some limitations, such as their lower biocompatibility as well as the lack of cell-specific recognition and attachment moieties [52].

In this way, researchers often adopt the production of hybrid nanofibrous mats, i.e., blends of synthetic and natural polymers, which allow the best compromise between the physical and biological properties to be found [58]. Furthermore, in the case of the asymmetric electrospun membranes, the selection of the polymers must take into consideration the different properties desired for the bottom and top layers. The external (top) layer should present a hydrophobic character (use of hydrophobic polymers) to avoid bacterial contamination and displays excellent mechanical properties (use of synthetic polymers) [22]. Otherwise, some studies demonstrated that the cells more easily adhere and proliferate in moderate hydrophilic wound dressings than in hydrophilic or hydrophobic ones [59]. Therefore, the inner (bottom) layer usually displays a hydrophilic character facil- 
itating the cell adhesion, proliferation, and migration [60]. Such also enables the capacity to absorb the wound exudate, and consequently maintain the adequate moist environment in the wound site [61].

\subsection{Asymmetric Electrospun Membranes}

The production of asymmetric electrospun membranes can also be accomplished by promoting the layer-by-layer assembly of different nanofiber-based structures (Table 1) [62]. Such is usually accomplished through the formation of one layer on the top of an already produced layer, hence mimicking both epidermis and dermis layers of the skin [62]. The external layer is often composed of smaller-sized hydrophobic nanofibers, which allow for the construction of a denser structure with small pores that protects the wound site against microorganisms invasion [27]. Additionally, polymers with strong mechanical properties, such as PCL and poly(L-lactic acid), are usually selected for assembling this layer since these materials confer mechanical resistance to the asymmetric electrospun membrane [55]. Otherwise, the bottom layer presents a porous interconnected 3D network with hydrophilic nanofibers that mimics the ECM [54]. Such promotes a moist environment that supports cell migration, adhesion, and proliferation $[43,63]$. Therefore, the combination of these two electrospun layers results in asymmetric membranes with enhanced biological performance (Table 2) [21,42,43].

Chanda et al. produced a CS-PCL/HA asymmetric electrospun construct to obtain an asymmetrical membrane with enhanced mechanical stability and capacity to perform wound bed hydration [26]. In this process, the HA-poly(ethylene oxide) solution was electrospun in the assembled CS-PCL nanofibrous top layers and crosslinked with glutaraldehyde vapor to obtain the bilayered (CS-PCL/HA) membrane. The CS-PCL/HA asymmetric membrane exhibited fibers with an average diameter of $362.2 \pm 236 \mathrm{~nm}$, which are similar to those found in collagen fibers of ECM (50 to $500 \mathrm{~nm}$ ). The membranes presented an overall porosity superior to $90 \%$ and a water vapor transmission rate of $\approx 2500 \mathrm{~g} \times \mathrm{m}^{-2} \times$ day $^{-1}$. Further, the authors reported that the water contact angle decreased from $127 \pm 2^{\circ}$ in single PCL electrospun membrane to $82.4 \pm 6.4^{\circ}$ in the CS-PCL/HA asymmetric membrane, a feature that is responsible for an increase in the swelling capacity from 105 to $135 \%$ (Figure 3). Otherwise, the CS-PCL/HA asymmetric membranes presented a bacterial adhesion 3.9-times inferior to the single PCL electrospun membrane and increased cytocompatibility [26].

Similarly, Chen et al. developed a CS/poly(L,D-lactic acid) (PDLLA) asymmetric electrospun membrane [64]. For this purpose, PDLLA nanofibers were randomly deposited in a static collector creating the bottom layer, which was subsequently coated with aligned CS nanofibers using a rotating collector at $1000 \mathrm{rpm}$. The resulting asymmetric membrane presented a CS top layer with small pore size and dense structure due to the packed small-sized nanofibers (i.e., $243 \mathrm{~nm}$ ) covering a highly porous PDLLA fibrous layer ( $2.8 \mu \mathrm{m}$ average fiber diameter and a surface pore size of about $12.18 \pm 1.7 \mu \mathrm{m})$. These authors observed that the CS/PDLLA asymmetric electrospun membrane presented enhanced HT1080 cell viability and infiltration when compared to single PDLLA fibrous mats and films. Moreover, in in vivo assays, the CS/PDLLA dual-layer membrane allowed the cell infiltration up to $32.5 \mu \mathrm{m}$ in depth, which contributed to the restoration of both epidermis and dermis layers by enhancing the regeneration of keratinocytes and fibroblasts, respectively. In this way, this asymmetric membrane allowed a faster restoration of the skin's structure and function when compared to the gauze, PDLLA film, or fibers [64].

In a different approach, Wu et al. developed an asymmetric electrospun membrane composed of a hydrophobic top layer with $\beta$-glucan butyrate nanofibers and a hydrophilic $\beta$-glucan acetate (BGA) nanofibrous inner layer (BGE-B asymmetric membrane) [61]. The assembly of the BGE-B membrane was achieved through the electrospinning of a $\beta$-glucan butyrate (BGB) solution onto the already assembled BGA nanofibrous mats. The BGA nanofibrous mats presented an average width of $150 \pm 58 \mathrm{~nm}$, a hydrophilic character (contact angle decreased from 86 to $0^{\circ}$ within $10 \mathrm{~s}$ ), and a high swelling capacity $(400 \%)$. In 
turn, the BGB layer presented a mean fiber diameter of $410 \pm 186 \mathrm{~nm}$, high hydrophobicity (contact angle of $\left.126.4^{\circ}\right)$, and low swelling ratio $(\approx 20 \%)$. The authors also reported that NIH 3 T3 fibroblasts could adhere and proliferate on the BGE-B membrane, mainly in the BGA layer, whereas HaCaTs keratinocytes showed a homogeneous proliferation in both sides of the asymmetric membrane. Moreover, the in vivo assays performed on a full-thickness mouse skin wound model demonstrated that on day 14, the group treated with BGE-B membrane exhibited a reduction in the wounded area of $83.1 \%$, contrasting with the 57.5 and $26.2 \%$ obtained in the gauze and control groups, respectively. Further, histological data revealed that the BGE-B membrane increased the epithelization process, and the structure of the newly formed tissue was quite similar to that of normal skin [61].

A
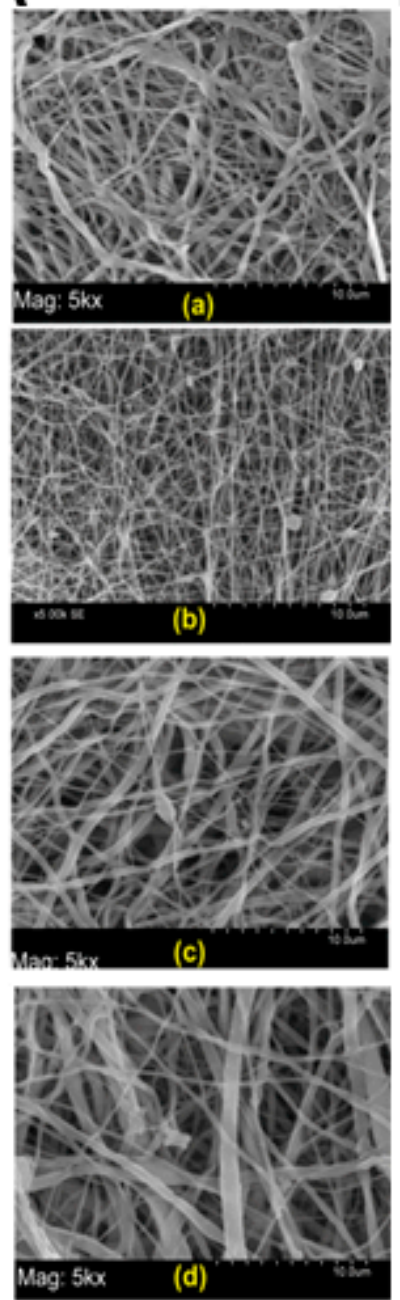

B

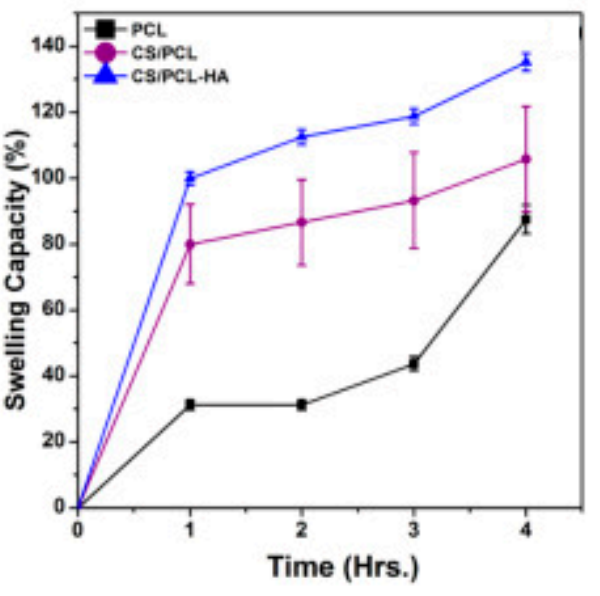

D

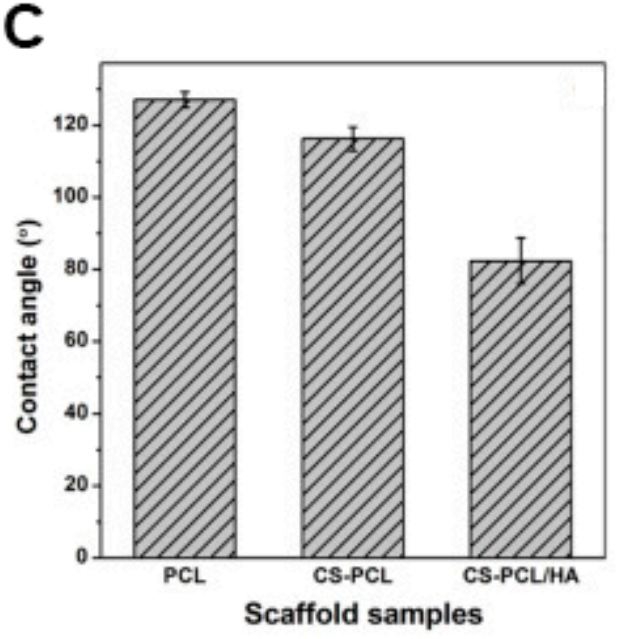

Figure 3. (A) SEM photomicrographs, with magnification of 5000 $\times$, of electrospun scaffolds of (a) poly(caprolactone) (PCL), (b) chitosan (CS)/PCL, (c) hyaluronic acid/polyethylene oxide (HA/PEO), (d) CS/PCL-HA. Physicochemical properties of only PCL membrane, CS-PCL membrane (top layer), and CS-PCL/HA asymmetric membrane; (B) swelling capacity of the scaffolds; (C) water contact angles of the scaffolds; (D) porosity of the scaffolds. Reprinted with permission from [26], Elsevier, 2018. 


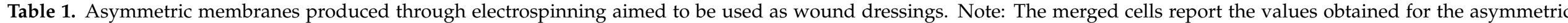
electrospun membranes.

\begin{tabular}{|c|c|c|c|c|c|c|c|c|c|}
\hline $\begin{array}{c}\text { Main } \\
\text { Polymer in } \\
\text { Top Layer }\end{array}$ & Layer & $\begin{array}{l}\text { Composition } \\
\text { of the Layers }\end{array}$ & $\begin{array}{l}\text { Fibers Average } \\
\text { Diameter (nm) }\end{array}$ & Porosity (\%) & $\begin{array}{l}\text { Water Contact } \\
\text { Angle }\end{array}$ & $\begin{array}{c}\text { WVTR } \\
\left(\mathrm{g} \times \mathrm{m}^{-2} \times \text { day }^{-1}\right)\end{array}$ & Swelling Capacity & Degradation Profile & Ref \\
\hline \multirow{15}{*}{ PCL } & Top layer & PCL; PLA & $691 \pm 282$ & \multirow[b]{2}{*}{ N.A. } & $126.8 \pm 5.7^{\circ}$ & \multirow[b]{2}{*}{ N.A. } & \multirow[b]{2}{*}{ N.A. } & $1.54 \pm 0.22 \%$, PBS, $\mathrm{pH} 7.4,3$ days & \multirow[b]{2}{*}{ [55] } \\
\hline & Bottom layer & GelMA; ChMA & $477 \pm 228$ & & $\begin{array}{c}88.2 \pm 6.1^{\circ} \text { to } 46.7 \pm \\
2.2^{\circ} \text { after } 20 \mathrm{~s}\end{array}$ & & & $5.63 \pm 0.21 \%, \mathrm{PBS}, \mathrm{pH} 7.4,3$ days & \\
\hline & Top layer & CS; PCL & $370 \pm 264$ & \multirow{2}{*}{$\approx 96.1$} & \multirow{2}{*}{$82.4 \pm 6.4^{\circ}$} & \multirow{2}{*}{$\approx 2536$} & \multirow{2}{*}{$\approx 135.2 \%, \mathrm{PBS}, \mathrm{pH} 7.4,4 \mathrm{~h}$} & $30 \%$, PBS, pH 5.5, 15 days & \multirow{2}{*}{ [26] } \\
\hline & Bottom layer & HA; PEO & $136 \pm 61$ & & & & & $\approx 4.8 \%, \mathrm{PBS}, \mathrm{pH} 7.4,15$ days & \\
\hline & Top layer & PCL & $300 \pm 50$ & \multirow[b]{2}{*}{ N.A. } & $160^{\circ}$ & \multirow[b]{2}{*}{ N.A. } & \multirow[b]{2}{*}{ N.A. } & \multirow[b]{2}{*}{ N.A. } & \multirow[b]{2}{*}{ [65] } \\
\hline & Bottom layer & $\begin{array}{c}\mathrm{SAG} ; \mathrm{ZnO} \\
\text { nanoparticles }\end{array}$ & $100 \pm 30$ & & $30^{\circ}$ & & & & \\
\hline & Top layer & PCL & $360 \pm 68$ & \multirow{2}{*}{ N.A. } & $\begin{array}{l}\text { Sample I: } 135^{\circ} \\
\text { Sample II: } 120^{\circ} \text { to } \\
119^{\circ} \text { after } 20 \mathrm{~s}\end{array}$ & \multirow{2}{*}{$\begin{array}{c}\text { Sample I: } 2280 \pm \\
\text { 153-2992 } \pm 72 \\
\text { Sample II: } 2506 \pm \\
42-4552 \pm 82\end{array}$} & \multirow{2}{*}{$\begin{array}{c}\text { Sample I: } 400 \% \text { in TRIS, } \\
\text { pH } 8,2 \mathrm{~h} \text {; after } 24 \mathrm{~h} \text {, } \\
\text { medium changed to AES, } \\
\text { pH 5, swelling decreased } \\
\text { to } 250 \% \\
\text { Sample II: } 350 \% \text {, TRIS, } \\
\text { pH 8, } 2 \text {; after } 24 \mathrm{~h}, \\
\text { medium changed to AES, } \\
\text { pH 5, swelling decreased } \\
\text { to } 300 \%\end{array}$} & \multirow{2}{*}{$\begin{array}{l}\text { Sample I: } \approx 2.9 \% \text { in TRIS, } \mathrm{pH} 8 \text {; after } 1 \text { week, } \\
\text { medium changed to PBS, } \mathrm{pH} 7.4 \text {, weight } \\
\text { loss increased to } 3.5 \% \text {; after another } 1 \text { week, } \\
\text { medium changed to AES, } \mathrm{pH} 5 \text {, weight loss } \\
\text { increased to } \approx 4.2 \% \\
\text { Sample II: } \approx 4.0 \% \text { in TRIS, } \mathrm{pH} 8 \text {; after } 1 \text { week } \\
\text { medium changed to PBS, } \mathrm{pH} 7.4 \text {, weight } \\
\text { loss decreased to } \approx 3.6 \% \text {; after another } 1 \\
\text { week, medium changed to AES, pH } 5, \\
\text { weight loss increased to } \approx 4.6 \%\end{array}$} & \multirow{2}{*}{ [66] } \\
\hline & Bottom layer & $\begin{array}{c}\text { PVAc } \\
\text { Sample I-PVAc in } \\
\text { DMF/ETOH; } \\
\text { Sample II-PVAc } \\
\text { in DMF) }\end{array}$ & $\begin{array}{l}\text { Sample I: } 600 \pm 100 \\
\text { Sample II: } 3000 \pm 1000\end{array}$ & & $\begin{array}{l}\text { Sample: } 120^{\circ} \text { to } 111^{\circ} \\
\text { after } 20 \mathrm{~s} \\
\text { Sample II: } 76^{\circ} \text { to } 27^{\circ} \\
\text { after } 20 \mathrm{~s}\end{array}$ & & & & \\
\hline & Top layer & HA; PCL & $472 \pm 192$ & $90.40 \pm 4.25$ & $120.20 \pm 0.85^{\circ}$ & $1762.91 \pm 187.50$ & N.A. & $\approx 10 \%, \mathrm{PBS}, \mathrm{pH} 5.5,7$ days & [28] \\
\hline & Top layer & PCL & $385 \pm 134$ & $55 \pm 5$ & $126.2 \pm 1.21^{\circ}$ & \multirow{2}{*}{$1252.35 \pm 21.22$} & \multirow{2}{*}{$\begin{array}{c}\text { Ratio } \approx 20, \text { PBS, } \mathrm{pH} 5, \\
30 \text { days }\end{array}$} & \multirow{2}{*}{$\begin{array}{c}\approx 30 \%, \text { PBS } \\
\text { containing lysozyme, } 30 \text { days }\end{array}$} & \multirow{2}{*}{ [67] } \\
\hline & Bottom layer & CS; AV; PEO & $152 \pm 54$ & $97.8 \pm 4.5$ & $69.06 \pm 3.78^{\circ}$ & & & & \\
\hline & Top layer & SF; PCL & $615.9 \pm 190.4$ & \multirow{2}{*}{$74.78 \pm 6.98$} & $103.10 \pm 6.57^{\circ}$ & \multirow{2}{*}{$2070.62 \pm 102.52$} & \multirow{2}{*}{$\begin{array}{l}\text { Ratio } \approx 42, \mathrm{PBS}, \mathrm{pH} 8, \\
\text { Ratio } \approx 39.4, \mathrm{PBS}, \mathrm{pH} 5\end{array}$} & \multirow{2}{*}{$23 \%, \mathrm{PBS}, \mathrm{pH} 7.4,7$ days } & \multirow{2}{*}{ [20] } \\
\hline & Bottom layer & SF; HA; THY & $412.7 \pm 106.7$ & & $38.77 \pm 5.32^{\circ}$ & & & & \\
\hline & Top layer & PCL; mupirocin & $1031 \pm 227$ & \multirow{2}{*}{$\approx 78.2$} & $246+46^{\circ}$ & NA & $620 \%$ PRS & $U_{0}$ & {$[68]$} \\
\hline & Bottom layer & CS; LID & $735 \pm 152$ & & 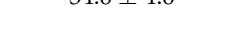 & N.T. & & & \\
\hline & Top layer & PeCL & 539 & & $117^{\circ}$ & & & & \\
\hline PeCL & Bottom layer & $\begin{array}{c}\text { PDO; } \mathrm{TiO}_{2} \\
\text { nanoparticles } \\
\text { (concentration of } \\
\text { 3\% (PP3T5T) and } \\
\text { 5\% (PP5T5T)); } \\
\text { TTC }\end{array}$ & $\begin{array}{l}\text { PP3T5T: } 611 \\
\text { PP5T5T: } 679\end{array}$ & N.A. & $\begin{array}{l}\text { PP3T5T }-48^{\circ} \\
\text { PP5T5T }-79^{\circ}\end{array}$ & N.A. & N.A. & N.A. & [69] \\
\hline
\end{tabular}


Table 1. Cont.

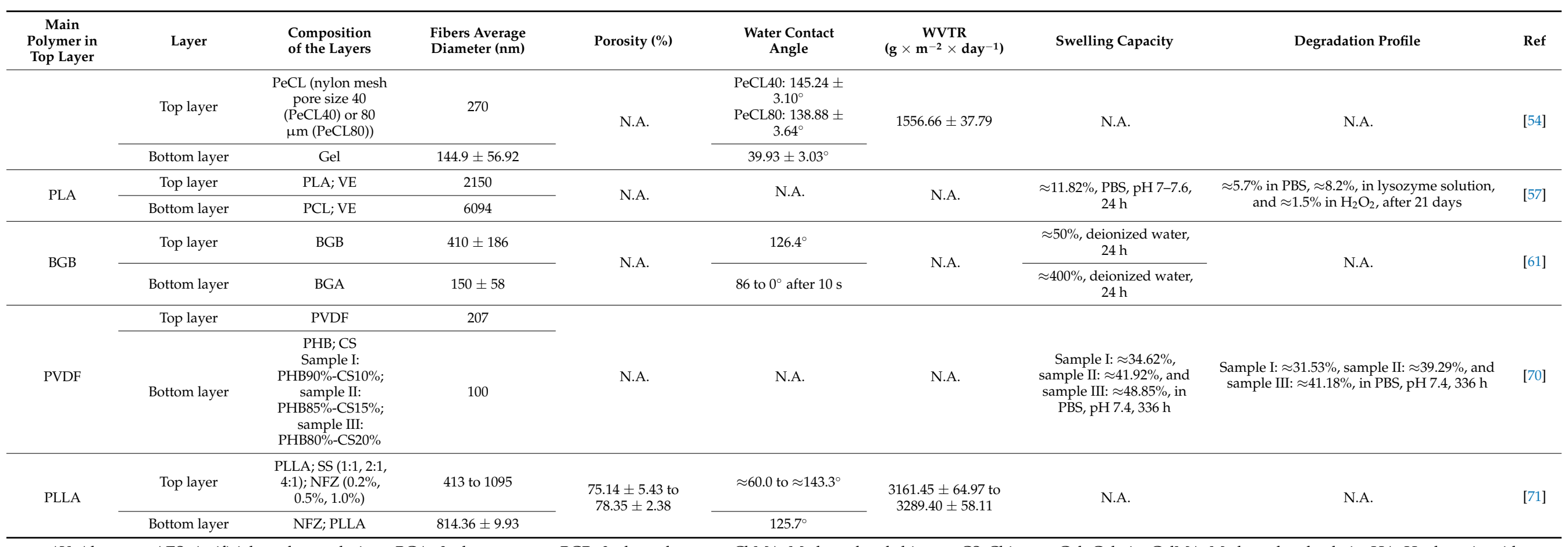

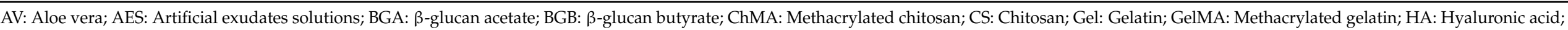

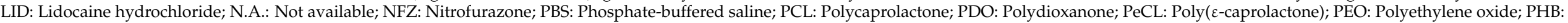

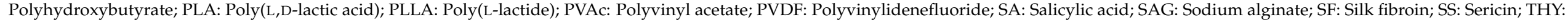

Thymol; TRIS: Tris(hydroxymethyl)aminomethane; VE: Vitamin E derivative; ZN: Zein. 
Table 2. Biological performance of the asymmetric membranes produced through electrospinning aimed to be used as wound dressings.

\section{Composition}

Antibacterial Activity

\section{Cell Behavior

Cell Behavior

Fibroblasts cellular viability of $\approx 101.1 \%$ and

$\approx 106.7 \%$, for the top and bottom layer,

$$
\text { respectively, after } 7 \text { days; }
$$

PCL-PLA/GelMA-ChMA

N.A.

N.A.

After seven days, a continuous layer of cells

with typical fibroblastic morphology and

lamellipodia connecting to surrounding

mesh was observed
The optical density of E. coli was $\approx 0.09$ for asymmetric membrane

CS-PCL/HA and $\approx 0.37$ for the control (PCL), after $24 \mathrm{~h}$ of incubation
Vero cells viability of $\approx 147.52 \%$, after 5 days;

Vero cells adhered to the asymmetric membrane showed a good cell-cell

interaction as well as an improved cell/fibrous scaffold integration, after 5 days

Efficient attachment of fibroblast cells to the membrane, after 5 days of incubation; Infiltration of fibroblast cells into

CS/PDLLA

N.A.

N.A.

CS/PDLLA membranes up to a depth of

$$
\approx 32.5 \mu \mathrm{m}
$$

The proliferation of fibroblast cells on the top and bottom layer was $\approx 184.41 \%$ and $\approx 208.68 \%$, respectively, after 7 days;

$\mathrm{BGB} / \mathrm{BGA}$ N.A. N.A.

The proliferation of keratinocytes on the top and bottom layer was $\approx 190.18 \%$ and $\approx 183.74 \%$, respectively, after 7 days
Wound Healing
The histology analysis, after 7 days of the wound treatment with the

asymmetric membrane, demonstrated that the epidermis and dermis layer were gradually restored with the

successful regeneration of keratinocytes

The asymmetric membranes induced the reduction of the wound size in $\approx 83.1 \%$ after 14 days;

The histology analysis of the wound

covered with the asymmetric membrane

showed the re-epithelialization and a

structure resembling the normal skin,

with skin-like organized collagen fibers and fibroblasts, respectively

The membrane showed excellent activity against $S$. aureus $(35 \mathrm{~mm}$ of inhibition zone), P. aeruginosa (30 $\mathrm{mm}$ of inhibition zone), and

E. coli (28 $\mathrm{mm}$ of inhibition zone)
N.A. 
Table 2. Cont. over time;

Completely regenerated epidermis and dense dermis, and continuous and uniform granulation tissue on day 14; The relative collagen content on day 14

$$
\text { was } 59.52 \% \text {; }
$$

The top layer exhibited lower

PeCL(nylon mesh pore size bacterial adhesion in comparison 40)/Gel-pio to the control, against S. aureus, E. coli, and $P$. aeruginosa
The viabilities of fibroblast cells and HUVEC s were $\approx 179.38 \%$ and $\approx 353.85 \%$, respectively, after 3 days;

The percentages of fibroblast cells and HUVECs migration were $61.54 \%$ and $68.57 \%$, respectively
The asymmetric membranes group showed the highest density of newly formed blood vessels $(\approx 30.32$ mature

vessels per field) after 7 days;

The asymmetric membranes group showed the most potent effect on cell proliferation (higher Ki67 expression, $\approx 73.23$ positive cells per field)

\section{Type 1 Diabetic Rat:}

Showed the fastest wound healing effect; The wounds treated with PCL40/Gel-pio were almost completely closed on day 14 Showed the higher density of collagen fibers $(\approx 61.46 \%)$ after 7 days; Showed the highest density of newly formed blood vessels $(\approx 32.27$ vessels per field) after 5 days, and decreased to the day 14 ( $\approx 12.69$ vessels per field);

The asymmetric membranes group showed the most potent effect on cell proliferation (higher Ki67 expression, $\approx 56.55$ positive cells per field), on day 14 
Table 2. Cont.

\section{Composition}

\section{Cell Behavio}

viability of $\approx 87.44 \%$, after 10

$$
\text { days; }
$$

The surface of the membrane was highly

colonized by fibroblast cells, and the cells' attachment inside the pores of the membranes was also observed, after 10 days

\section{Wound Healing}

After 14 days, the chick chorioallantoic membrane assay revealed the complete coverage of the asymmetric membrane with the newly formed vessels ( $\approx 48.99$ blood vessels)

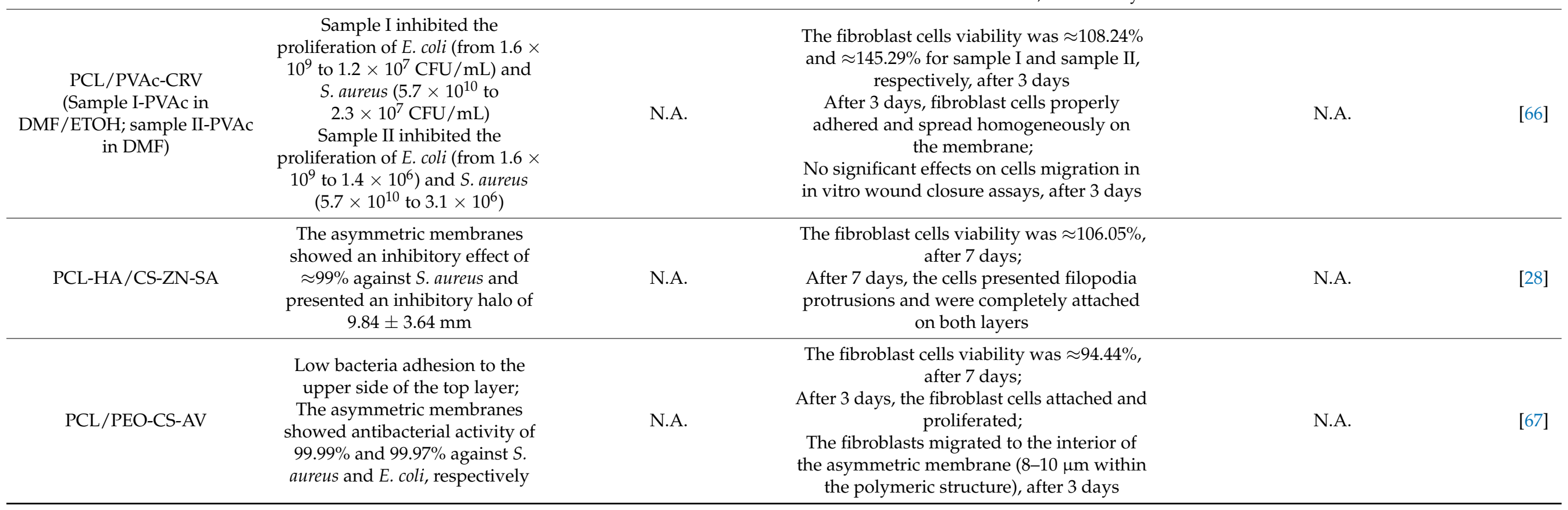


Table 2. Cont.

\begin{tabular}{|c|c|c|c|c|c|}
\hline Composition & Antibacterial Activity & Antioxidant Activity & Cell Behavior & Wound Healing & Ref \\
\hline PCL-SF/SF-HA-THY & $\begin{array}{l}\text { The PCL-SF layer avoided the } \\
\text { bacterial infiltration of S. aureus } \\
\text { and P. aeruginosa; } \\
\text { The SF-HA-THY layer showed } \\
\text { antibacterial activity of } 87.42 \% \\
\text { (and an inhibition zone of } \\
\approx 69.90 \% \text { ) and } 58.43 \% \text { (and an } \\
\text { inhibition zone of } \approx 52.38 \% \text { ), } \\
\text { against S. aureus and } \\
\text { P. aeruginosa, respectively }\end{array}$ & $\begin{array}{l}\text { Antioxidant activity of } \\
9.22 \% \text { and } \approx 45.64 \% \text { for } \\
\text { the PCL-SF and } \\
\text { SF-HA-THY membranes, } \\
\text { respectively, after } 8 \mathrm{~h} \\
\text { of incubation }\end{array}$ & $\begin{array}{l}\text { The fibroblast cells viability was } \approx 93.44 \% \\
\text { and } \approx 93.82 \% \text { for the PCL-SF and } \\
\text { SF-HA-THY membranes, respectively, after } \\
\quad 7 \text { days; } \\
\text { Both membranes promoted the cell } \\
\text { adhesion, but in the SF_HA_THY layer, the } \\
\text { fibroblast cells appeared to present more } \\
\text { filopodia protrusions, higher cell adhesion, } \\
\text { and proliferation }\end{array}$ & N.A. & [20] \\
\hline $\begin{array}{c}\mathrm{PeCL} / \mathrm{PDO}-\mathrm{TiO}_{2} \\
\text { nanoparticles (concentration } \\
\text { of 3\% (PP3T5T) and 5\% } \\
(\text { PP5T5T))-TTC }\end{array}$ & $\begin{array}{l}\text { PP3T5T presented an inhibition } \\
\text { zone of } 12.78 \pm 2.5 \text { and } \\
16.28 \pm 4.7 \mu \mathrm{m} \text {, against } S \text {. aureus } \\
\text { and } E . \text { coli, respectively; } \\
\text { PP5T5T presented an inhibition } \\
\text { zone of } 26.14 \pm 6.7 \text { and } \\
36.94 \pm 5.6 \mu \mathrm{m} \text {, against } S \text {. aureus } \\
\text { and } E . \text { coli, respectively }\end{array}$ & N.A. & $\begin{array}{c}\text { The fibroblast cells proliferation was } \\
\approx 107.77 \% \text { and } \approx 110.83 \% \text { for PP3T5T and } \\
\text { PP5T5T, respectively, after } 6 \text { days; } \\
\text { The fibroblast cells penetrated up to a depth } \\
\text { of } 40 \text { and } 35 \mu \mathrm{m} \text { for PP3T5T and PP5T5T, } \\
\text { respectively, after } 4 \text { days }\end{array}$ & N.A. & [69] \\
\hline
\end{tabular}

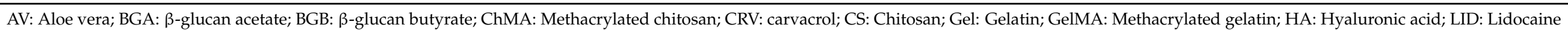

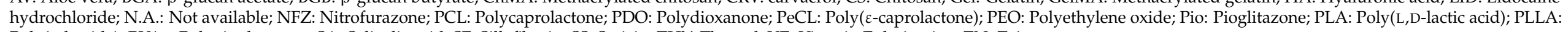
Poly(L-lactide); PVAc: Polyvinyl acetate; SA: Salicylic acid; SF: Silk fibroin; SS: Sericin; THY: Thymol; VE: Vitamin E derivative; ZN: Zein. 


\section{Electrospun Asymmetric Membranes as Delivery Systems of Biomolecules}

Apart from the structural advantages of asymmetric electrospun membranes, the nanofibers present in their structure can also incorporate bioactive agents for increasing its antibacterial efficacy and/or enhance the wound healing process (Figure 4). Table 3 provides an overview of the biologic properties of asymmetric membranes produced through electrospinning aimed to be used as wound dressings.

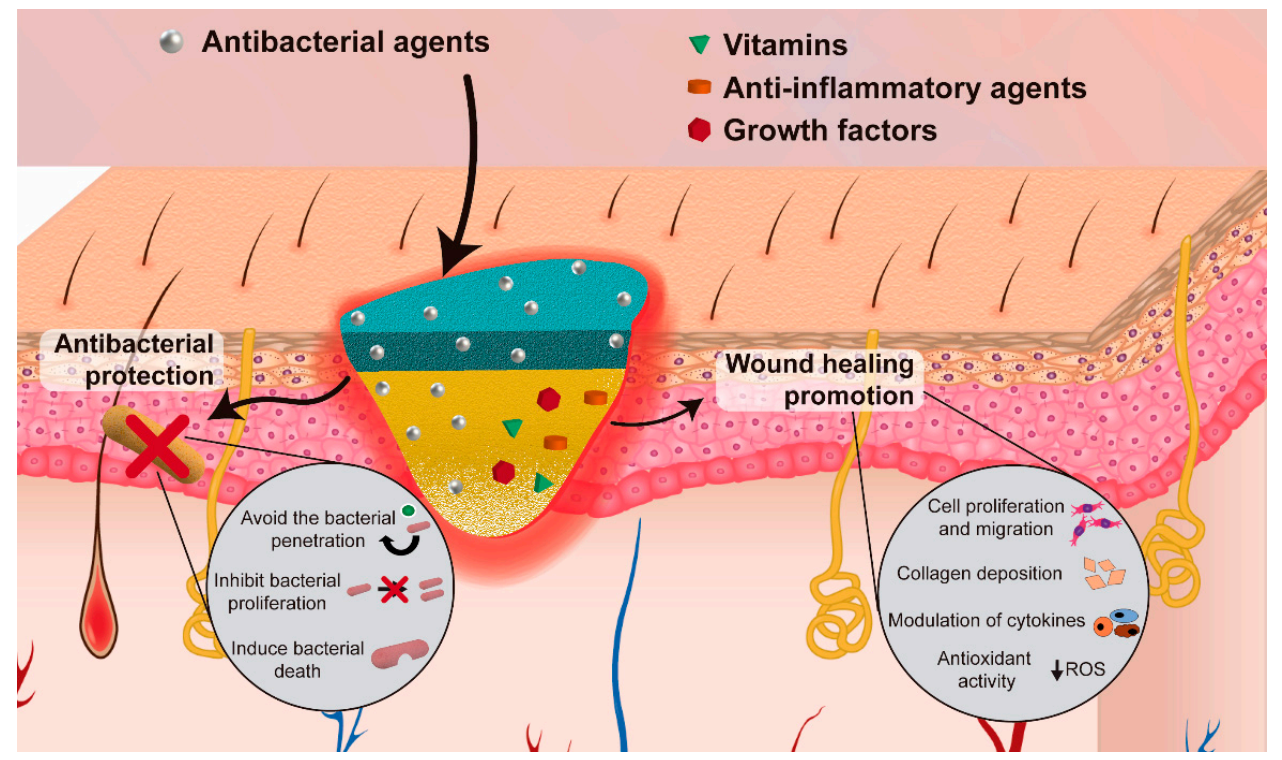

Figure 4. Illustration of the incorporation of bioactive agents to improve the antibacterial efficacy and/or enhance the wound healing process.

The electrospun membranes are recognized as good drug carriers due to their high surface area to volume ratio, connected porosity, high drug loading capacity, and tunable release profile [72]. The release of biomolecules from the nanofibers occurs mainly through three mechanisms desorption from the surface, diffusion through fibers, and fiber degradation. The desorption consists of a burst release due to the proximity between the biomolecule encapsulated on the fiber surface and the surrounding liquid [52]. The mechanism based on the biomolecules' diffusion is characterized by their transport through the channels and pores of the fibers, mainly in the case of non-biodegradable polymers [52,73]. Otherwise, the use of biodegradable polymers leads to the release of the biomolecule due to the degradation of the polymeric matrix. This degradation creates additional spaces in the nanofibers' structure, which facilitates the release of the encapsulated biomolecules into the surrounding medium [52,73]. Additionally, the drug release profile can also be affected by several factors, such as the fibers' composition (hydrophilicity, hydrophobicity, and biodegradability of the polymers and biomolecules), the interactions between the polymer/biomolecule/solvent, and the incorporation technique $[74,75]$. Furthermore, the fiber structure, i.e., morphology, diameter, porosity, and ratio (polymer-encapsulated drug), can also affect the release [72]. In respect to the composition, hydrophilic drugs present a more effective encapsulation and homogeneous distribution within hydrophilic polymers, while the utilization of hydrophobic polymers shows better results to encapsulate hydrophobic drugs [52,76]. It is worth noticing that hydrophilic drugs usually present faster drug releases (i.e., burst release) due to their high solubility in the release media [52]. Furthermore, changes in the matrix structure can also influence drug release. For example, an increase in the surface area-to-volume ration and porosity of fibrous mats leads to a burst release of the drugs from the nanofibers [77]. Moreover, the development of fibers with a multilayer structure enables a more sustained release, or even the encapsulation of different therapeutic agents in different layers, each one presenting a release profile according to its location in the fiber [62]. Another strategy that has been emerging is the use of stimuli-responsive materials which facilitate the control of the drug release both temporally and spatially [51,78]. Temperature [79], ultrasound [80], light [81], 
and endogenous changes in the $\mathrm{pH}$ value [82], are some examples of the stimulus that can be explored to trigger the drug release by inducing changes in the polymeric nanofibers.

The incorporation of therapeutic or antimicrobial agents can be performed before (e.g., blend, co-axial, and emulsion) or after (e.g., physical adsorption, layer-by-layer assembly, and chemical immobilization) the electrospinning process [43]. In the blend electrospinning, the drug is incorporated in the polymeric solution and the nanofibers are produced with the drug uniformly distributed within their structure [83]. The resulting nanofibrous mats often exhibit a burst release dependent on polymer degradation and drug diffusion from the nanofiber [24]. Alternatively, core-shell nanofibers encapsulate the therapeutic agents within the nanofiber core, which is enclosed in an external polymeric layer that provides a more controlled and prolonged drug release [51]. These nanostructures can be produced by co-axial or by emulsion electrospinning. The co-axial electrospinning uses concentric needles to create a layer-by-layer organization, while the emulsion relies on the utilization of an aqueous solution and an oil phase that are emulsified together to create the core-shell nanofibers [75,76]. Otherwise, the drug loading can be achieved via post-electrospinning techniques that comprise the adsorption of the drug onto the surface of the fibers through non-covalent or covalent interactions [76]. The physical adsorption of therapeutic agents is based on the creation of non-covalent interactions (electrostatic and/or hydrophobic) between the nanofibers and the drug, while the chemical approaches require the immobilization of the therapeutic agents via covalent bonds. Such enables the development of nanofiber membranes with different drug release profiles, i.e., usually non-covalent interactions lead to a faster and poorer control over the drug release, whereas a sustained/stimuli-responsive release can be achieved using covalent binding [24,76]. These different approaches allow the selection of the optimal loading method according to the bioactive agent as well as the possibility to develop wound dressings with tailored release profiles [24]. For example, Buck et al. compared the antimicrobial and release properties of PLGA electrospun fibers incorporating ciprofloxacin (CIP) through blend or physical adsorption [56]. The blend nanofibers were produced by the electrospinning of a CIP-PLGA solution, whereas in the physical adsorption PLGA nanofibrous mats were immersed in a CIP solution and dried. The authors observed that upon the immersion of PLGA mats in phosphate-buffered saline solution (PBS) (pH 7.4), at $37^{\circ} \mathrm{C}$, the $\mathrm{CIP}$ loading by physical absorption resulted in a fast release, reaching its maximum at $6 \mathrm{~h}$. In turn, the blend counterparts presented a sustained release for $48 \mathrm{~h}$. Moreover, the authors also reported that the antibacterial capacity against Pseudomonas aeruginosa (P. aeruginosa), Staphylococcus aureus (S. aureus), and S. epidermidis was influenced by the loading method. In fact, the physical absorption resulted in higher-sized inhibitory halos, whereas the blended disks retained a higher percentage of the inhibitory zone after $48 \mathrm{~h}$ of incubation [56]. In turn, Jin and co-workers compared the incorporation of multiple epidermal induction factors (EIF) by coaxial electrospinning and blend electrospinning, in poly(L-lactic acid)-co-poly( $\varepsilon$ caprolactone) (PLLCL) and Gel nanofibers (Gel-PLLCL-EIF (coaxial electrospinning) and Gel-PLLCL-EIF (blend electrospinning), respectively) [84]. To accomplish that, core-shell nanofibers were produced by electrospinning a Gel-PLLCL mixture as an outer solution and $5 \%$ bovine serum albumin with a concentrated epidermal induction medium (CEIM, composed of epidermal growth factor (EGF), insulin, hydrocortisone, and retinoic acid) as core solution. Alternatively, the Gel-PLLCL-EIF (blend electrospinning) nanofibers were produced through the conventional electrospinning of the Gel-PLLCL-CEIM blend. These authors observed that the Gel-PLLCL-EIF (blend electrospinning) released $44.9 \%$ of its content in the first 3 days, reaching the maximum of $77.8 \%$ at day 15 , whereas the Gel-PLLCL-EIF (coaxial electrospinning) presented a stable and sustained release with $50.9 \%$ of EGF released at day 15. Such differences were attributed to the Gel-PLLCL outer layer in the core-shell nanofibers that acted as a barrier that diminished the initial burst release [84]. Apart from the structural organization, the drug release of the nanofibrous mats could also be controlled by the biodegradation profile of the polymers or using smart materials responsive to different stimuli [85]. For more information regarding the utilization of nanofibrous structures as drug delivery systems the readers are referred to [72,85-87]. 
Table 3. Asymmetric membranes produced through electrospinning aimed to be used as biomolecules delivery systems.

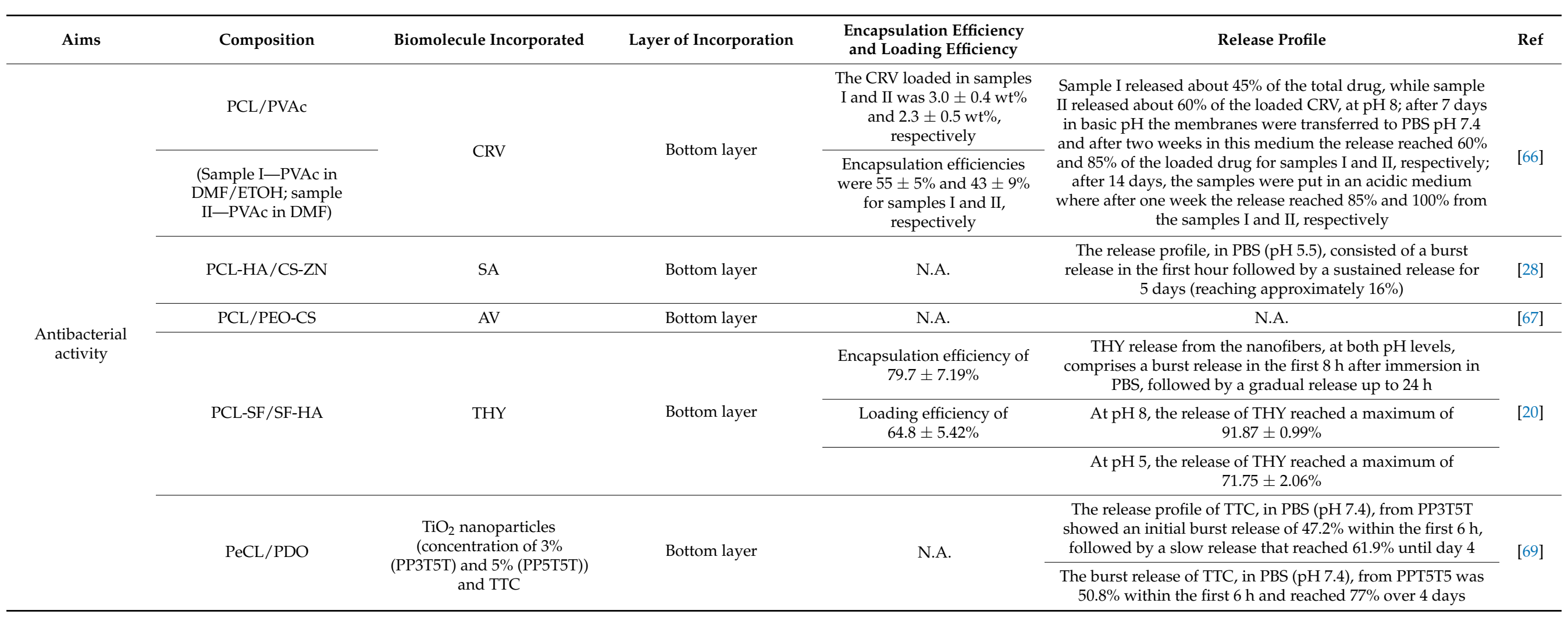


Table 3. Cont.

\begin{tabular}{|c|c|c|c|c|c|c|}
\hline Aims & Composition & Biomolecule Incorporated & Layer of Incorporation & $\begin{array}{l}\text { Encapsulation Efficiency } \\
\text { and Loading Efficiency }\end{array}$ & Release Profile & Ref \\
\hline & \multirow{3}{*}{ PLLA-SS/PLLA } & \multirow{3}{*}{ NFZ } & \multirow{3}{*}{ Both layers } & \multirow{3}{*}{ N.A. } & $\begin{array}{l}\text { The top PLLA-SS nanofibrous mats with } 0.2 \% \text { of NFZ, in PBS } \\
\text { (pH 7.4) presented a fast release profile with more than } 98 \% \\
\text { of NFZ detected in } 10 \text { min of incubation for every ratio }\end{array}$ & \multirow{3}{*}{ [71] } \\
\hline & & & & & $\begin{array}{l}\text { The PLLA bottom layer in PBS ( } \mathrm{pH} 7.4 \text { ) presented a more } \\
\text { controlled and sustained release, reaching } 17.6 \% \text { after } 48 \mathrm{~h}\end{array}$ & \\
\hline & & & & & $\begin{array}{c}\text { PLLA-SS(2:1)-0.2NFZ/PLLA-2NFZ, } \\
\text { PLLA-SS(2:1)-0.5NFZ/PLLA-2NFZ, and } \\
\text { PLLA-SS(2:1)-1.0NFZ/PLLA-2NFZ in PBS (pH 7.4) presented } \\
\text { a burst release of } 11.2 \%, 14.3 \% \text {, and } 28.4 \% \text {, respectively, and } \\
\text { the release amounts reached } 29.4 \%, 43.0 \% \text {, and } 53.9 \% \text {, } \\
\text { respectively, after } 48 \mathrm{~h}\end{array}$ & \\
\hline \multirow{4}{*}{$\begin{array}{l}\text { Wound healing } \\
\text { improvement }\end{array}$} & \multirow[b]{2}{*}{$\mathrm{PCL} / \mathrm{CS}$} & Mupirocin & Top layer & \multirow[b]{2}{*}{ N.A. } & $\begin{array}{l}\text { The initial burst release of LID reached } 66 \% \text { in the first hours } \\
\text { and increased gradually to } 85 \% \text { in the following } 6 \mathrm{~h} \text {, in PBS }\end{array}$ & \multirow[b]{2}{*}{ [68] } \\
\hline & & LID & Bottom layer & & $\begin{array}{l}\text { The release of mupirocin consisted in the release of } 57 \% \text { of } \\
\text { mupirocin in the first } 6 \mathrm{~h} \text {, followed by a sustained release } \\
(30 \% \text { was released in the following } 114 \mathrm{~h}) \text {, in PBS }\end{array}$ & \\
\hline & PeCL/Gel & Pio & Bottom layer & $\begin{array}{l}\text { Loading efficiency of } \\
\quad 56.16 \pm 7.45 \%\end{array}$ & $\begin{array}{l}\text { The Pio release rapidly reached } 40 \% \text { in day } 1 \text { and a long-term } \\
\text { release reached } 75 \% \text { in day 14, in PBS (pH 7.4) }\end{array}$ & [54] \\
\hline & PLA/PCL & VE & Both layers & N.A. & $\begin{array}{c}\text { The asymmetric membrane showed a sustained release of VE } \\
\text { over } 21 \text { days reaching a maximum of } 78 \% \text {, in PBS }\end{array}$ & [57] \\
\hline
\end{tabular}

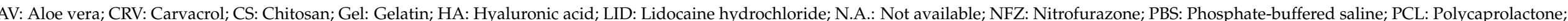

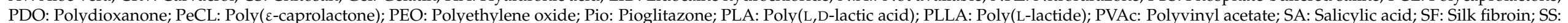

Sericin; THY: Thymol; VE: Vitamin E derivative; ZN: Zein. 


\subsection{Electrospun Asymmetric Membranes with Antibacterial Activity}

When the skin integrity is disrupted, the occurrence of infections leads to the deterioration of the granulation tissue, growth factor, and ECM components and, consequently, to the impairment of the wound healing process [85]. These infections can be caused by different bacteria, usually in initial stages the infections occur as a consequence of Gram-positive bacteria, such as S. aureus and Streptococcus pyogenes (S. pyogenes), while in later stages they are originated by Gram-negative bacteria, such as Escherichia coli (E. coli) and $P$. aeruginosa. In this way, the incorporation of antibiotics (e.g., CIP, gentamicin, and sulfadiazine), nanoparticles (e.g., silver, iron oxide, nitric oxide), and natural products (e.g., honey, essential oils, and CS) in wound dressing has been widely explored to prevent bacterial infections [14,85].

Among the different antibacterial agents, the incorporation of antibiotics in asymmetric electrospun membranes has been one of the most explored approaches [69,71]. Zhao et al. produced an asymmetric poly(L-lactide) (PLLA)-sericin (SS)/PLLA electrospun membrane loaded with nitrofurazone (NFZ) for wound dressing applications [71]. In this process, the NFZ was blended in the PLLA-SS and PLLA solutions before the electrospinning process. The NFZ-loaded PLLA bottom layer was produced over the NFZ-loaded PLLA-SS nanofibrous mats. The PLLA bottom layer presented fibers with an average diameter of $814 \mathrm{~nm}$. In turn, in the PLLA-SS mats, the average diameter of the nanofibers increased from 413 to $1095 \mathrm{~nm}$ by changing the PLLA-SS ratio from 4:1 to 1:1. Despite this variation, the asymmetric membranes presented a similar overall porosity ranging from $75.14 \pm 5.43 \%$ to $78.35 \pm 2.38 \%$. The authors observed that the NFZ presented a release profile dependent on the nanofibrous layer. The top PLLA-SS nanofibrous mats presented a fast release profile with more than $98 \%$ of NFZ detected in 10 min of incubation, independently of the PLLA-SS ratio. Otherwise, the PLLA bottom layer presented a more controlled and sustained release, reaching the $17.6 \%$ after $48 \mathrm{~h}$. Such difference is attributed to the possible interaction of NFZ with SS, a good water-soluble material that allows a faster drug diffusion upon its dissolution in the media. Moreover, the initial burst release of NFZ from the PLLA-SS layer is important for the elimination of bacteria that can be initially present on the wound site, whereas the more sustained release from the PLLA bottom layer can contribute to long-term antibacterial effects. The studies performed on E. coli and Bacillus subtilis demonstrated the SS intrinsic antibacterial activity, which was enhanced with the NFZ incorporation (larger inhibitory halos). In in vivo studies, the group treated with the NFZ-loaded asymmetric membranes showed a faster wound healing, i.e., 97 and $84 \%$ wound size reduction for the NFZ-loaded dual-layer membranes and commercial woven dressing, respectively [71].

Nevertheless, the rise of multidrug-resistant bacteria over the past years has highlighted the necessity to select and study new antibacterial agents. In this way, natural products have been screened to identify alternative antibacterial approaches. Among them, essential oils have been recognized due to their antioxidant, antiviral, anticancer, insecticidal, anti-inflammatory, anti-allergic, and antimicrobial properties [85]. The antibacterial activity of these natural products is mainly attributed to the phenolic compounds, specifically to thymol (THY) and carvacrol (CRV) [20,66]. Miguel et al. produced a silk fibroin (SF)-based asymmetric electrospun membrane loaded with THY for being applied in the wound healing [20]. The THY was blended in a SF-HA solution that was electrospun over the SF-PCL top layer and treated with ethanol vapor to improve the water stability of the SF. The SF-based asymmetric electrospun membrane presented an overall porosity of $74.78 \pm 6.98 \%$, a swelling capacity of $400 \%$, and nanofibers with a mean diameter of $615.9 \pm 190.4$ and $412.7 \pm 106.7 \mathrm{~nm}$ in the top SF-PCL and bottom SF-HA-THY layers, respectively. Moreover, the authors observed a burst release of THY in the first $8 \mathrm{~h}$, reaching a maximum of $91.87 \pm 0.99 \%$ at $\mathrm{pH} 8$ (Figure 5). Otherwise, the antibacterial assays performed with and P. aeruginosa revealed that the SF-PCL top membrane can avoid the infiltration of both bacteria through the bottom layer with an efficacy almost similar to the conventional filter paper. Further, the SF-HA-THY bottom membrane significantly inhib- 
ited the proliferation of S. aureus and P. aeruginosa (bacterial growth inhibition of $87.42 \%$ and $58.43 \%$, respectively) when compared to the SF-HA membrane (4.05\% and $3.42 \%)$ [20].

A

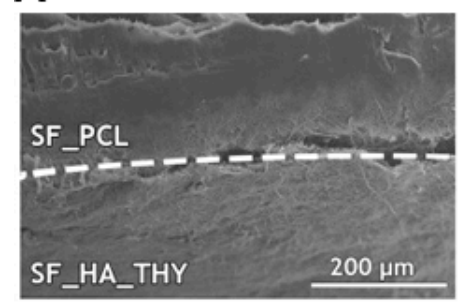

D

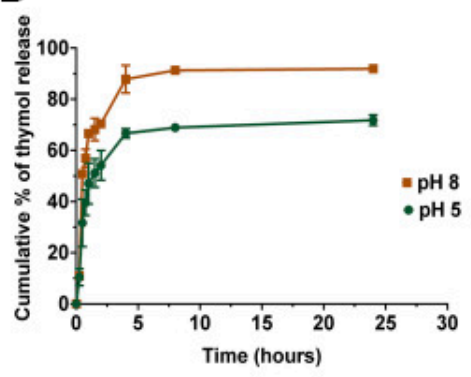

B

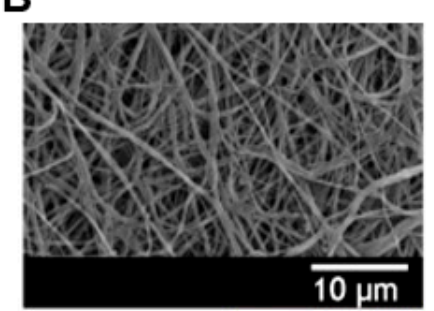

E
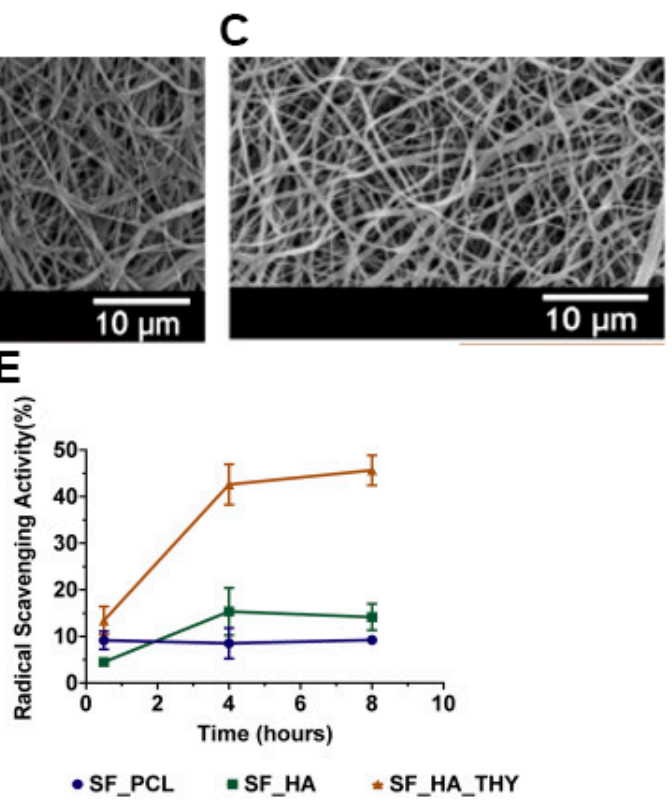

Figure 5. SEM images of (A) produced asymmetric membrane cross-section (top layer: SF_PCL; bottom layer: SF_HA_THY); (B) SF_PCL after the crosslinking process; (C) SF_HA_THY after the crosslinking process; (D) evaluation of the THY In Vitro release profile; (E) evaluation of the antioxidant activity of the SF-PCL membrane (top layer), SF-HA membrane (bottom layer) with or without THY. Reprinted with permission from [20], Elsevier, 2019.

In a similar approach, Aragón and co-workers produced a PCL/poly(vinyl acetate) (PVAc) asymmetric membrane loaded with CRV for increasing the antimicrobial capacity of the wound dressing [66]. The production of the asymmetric membrane was accomplished in a three-step process using a multi-jet electrospinning apparatus: 1) Deposition of PCL top layer; 2) multi-jet deposition of PCL and PVAc-CRV blend; and 3) deposition of PVAc-CRV bottom layer. The PCL/PVAc asymmetric membrane presented an overall porosity superior to $80 \%$, comprising a denser hydrophobic PCL top layer with a thickness around 100-120 $\mu \mathrm{m}$ and fibers with an average diameter of $360 \pm 68 \mathrm{~nm}$, a transition layer, and a loose spiderweb PVAc-CRV nanofibrous structure with an average diameter of $600 \pm 100 \mathrm{~nm}$. Moreover, the CRV release assays performed in conditions mimicking the wound site ( $\mathrm{pH} 8$ to 5 ) showed an initial burst release $\approx 45 \%$ after $24 \mathrm{~h}$, at $\mathrm{pH} 8$, followed by a sustained diffusion up to $85 \%$ at day 21 and $\mathrm{pH}$ progression from 8 to 7.4 and 5. Moreover, the authors reported that the PCL/PVAc-CRV asymmetric membrane significantly inhibited the proliferation of E. coli (from $1.6 \times 10^{9}$ to $1.2 \times 10^{7}$ ) and S. aureus $\left(5.7 \times 10^{10}\right.$ to $\left.2.3 \times 10^{7}\right)[66]$.

\subsection{Electrospun Asymmetric Membranes Loaded with Bioactive Molecules that Improve the Healing Process}

The wound healing process involves five different phases, namely hemostasis, inflammation, migration, proliferation, and remodeling. This complex process is based on a complex interaction between cells, growth factors, and cytokines [88]. In this way, tissue engineering researchers have been incorporating bioactive molecules in wound dressings to promote and improve the different phases of the healing process.

The delivery of vitamins can stimulate cell migration to the wound site, increase the collagen synthesis, enhance the angiogenesis, and modulate the inflammatory response leading to an improved skin regeneration [89]. Zahid and collaborators produced a PCL/PLA electrospun membrane enriched with $\alpha$-tocopherol acetate (vitamin E derivative- 
VE) for supporting the wound healing process [57]. The VE was blended both with PCL and PLA solutions, then the PLA-VE blend was electrospun over the assembled PCL-VE top layer using a rotating collector. The asymmetric membrane showed a sustained release of VE over 21 days reaching a maximum of $78 \%$. Further, the authors observed that the VE-loaded PCL/PLA asymmetric membrane was capable of promoting the NIH3T3 fibroblasts cell migration, adhesion, and proliferation. Additionally, the studies performed on chick chorioallantoic membrane showed that the group treated with VE-loaded PCL/PLA asymmetric membrane presented a higher number of blood vessels, i.e., 2-times superior to that detected on non-loaded PCL/PLA bilayers (Figure 6).

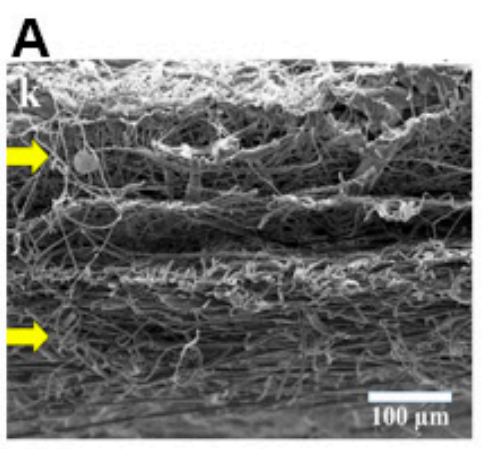

B

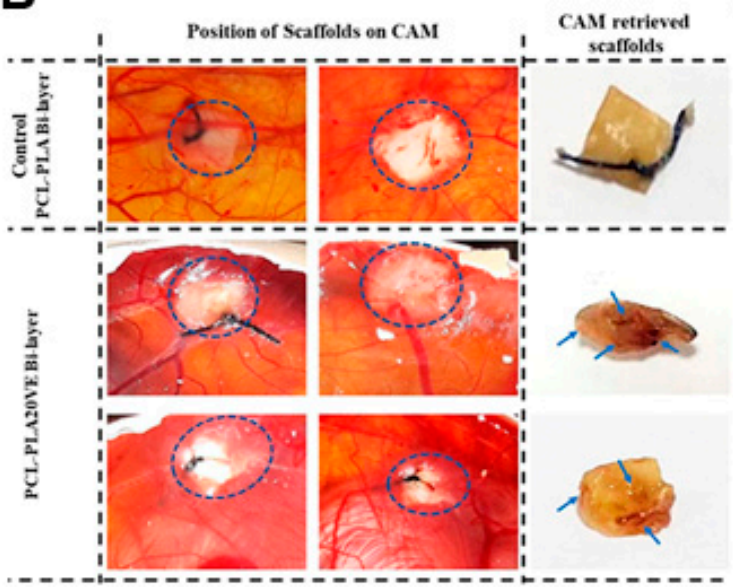

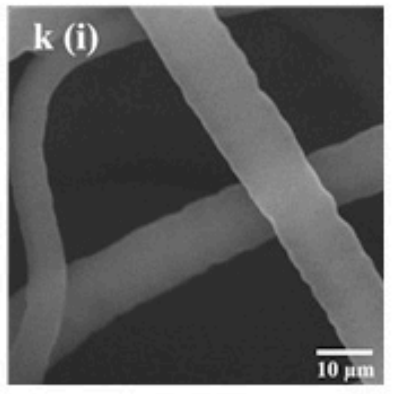

C
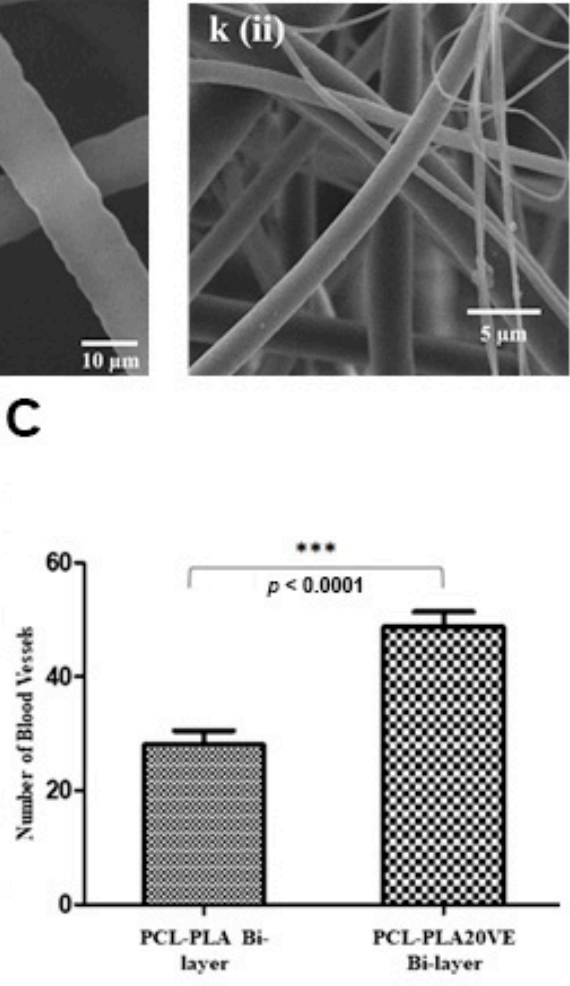

Figure 6. (A) SEM images of cross section of PCL-PLA20VE Bi-layer; k(i) PCL20VE; k(ii) PLA20VE. (B) Evaluation of angiogenic potential of the PCL/PLA asymmetric membranes with and without $20 \%$ of VE. The appearance and position of implanted membranes on CAM, at day 14 of fertilization, indicated by the circles. Blue arrows, on retrieved membranes, depict blood vessels infiltrated inside the explanted membrane. (C) Quantification of CAM assay by counting blood vessels around and inside the membranes, from the images taken at day 14, just before retrieving the membranes and sacrificing the eggs. The results are mean \pm S.D. $\left({ }^{* * *} p<0.0001\right)$ of 4 viable chicks surviving from original group of 7 fertilized eggs per group. Reprinted with permission from [57], Elsevier, 2019.

Otherwise, the asymmetric membranes can also be loaded with anti-inflammatory agents, such as curcumin, chrysin, ibuprofen, and pioglitazone (Pio) $[14,54,90]$. A chronic or uncontrolled acute inflammatory process could result in excessive production of inflammatory mediators, free radicals, and cytotoxic enzymes that could negatively impact on the healing process [85]. Yu et al. developed a poly( $\varepsilon$-caprolactone) (PeCL)/Gel nanofibrous asymmetric membrane loaded with Pio using a $40 \mu \mathrm{m}$-pore-size nylon mesh template [54]. The hydrophobic PeCL layer was electrospun on the top side of the nylon mesh template, whereas the hydrophilic Gel-Pio blend was produced on the bottom side and crosslinked with genipin. The resulting membrane is composed of $270 \mathrm{~nm}$ diameter PeCL nanofibers on top and $144 \mathrm{~nm}$ Gel nanofibers in the bottom layer. The Pio release from the PeCL/Gel asymmetric membrane rapidly reaches $40 \%$ in day 1 and stabilizes around $75 \%$ until day 14 . 
Bacterial adhesion tests performed with S. aureus, P. aeruginosa, and E. coli demonstrated that the PeCL top layer significantly reduced the number of adhered bacteria, particularly for $P$. aeruginosa and E. coli strains, due to its hydrophobicity (surface water contact angle of $145^{\circ}$ ). Furthermore, when compared to the non-loaded counterparts, the PeCL/Gel-Pio asymmetric membranes promoted the migration of both human skin fibroblasts and human umbilical vein endothelial cells. Moreover, the authors also observed a clear reticular vascular structure with more tube junctions and nodes in the HUVECs group treated with $\mathrm{PeCL} / \mathrm{Gel}$-Pio demonstrating its proangiogenic capacity. The in vivo assays performed on type 2 diabetic mice showed that the wounds treated with the PeCL/Gel-Pio asymmetric membrane were almost fully closed on day 10, whereas the same was only observed at day 14 in the groups treated with PeCL/Gel and Tegaderm. Further, at day 14, the $\mathrm{PeCL} / \mathrm{Gel}$-Pio group presented a relative collagen content almost 2-times superior to the remaining groups, being also observed in histological images' regular and orderly collagen arrangement as well as a smaller granulation tissue space [54].

\section{Conclusions and Future Perspectives}

Acute and chronic skin injuries continue to be a major health issue for the worldwide population. In this field, the electrospun asymmetric membranes have been emerging in recent years as promising wound dressings. These wound dressings are usually comprised by two different layers, (i) an epidermis-like layer with a dense structure that confers protection and mechanical stability, and (ii) a dermis-like layer with a loosened and porous structure that provides support for cell migration and proliferation, stimulates the angiogenesis, and allows the gaseous and fluid exchanges. Further, the nanofibrous structure of electrospun asymmetric membranes highly resembles the interconnected 3D network of the ECM and the native physical fibrillar structure of collagen. Additionally, the loading of bioactive molecules on electrospun asymmetric membranes can be achieved through different approaches (pre- or post- the electrospinning process).

Despite the electrospun asymmetric membranes' capacity to actively support, stimulate, and accelerate the wound healing process, further developments are still required to achieve optimal skin regeneration in humans. Although there are no asymmetric electrospun membranes in clinical trials, asymmetric structures (e.g., Apligraf ${ }^{\circledR}$, PolyActive ${ }^{\circledR}$, PermaDerm $^{\mathrm{TM}}$, and $\mathrm{OrCel}^{\circledR}$ ) have been used already as dermal/epidermal wound substitutes, demonstrating the potential of asymmetric membranes for application in skin regeneration, namely in the healing of full-thickness wounds. Furthermore, the incorporation of growth factors and proteins are already under development in electrospun membranes; however, the inclusion of them in asymmetric electrospun membranes may be an important factor to enhance its biological performance. In addition, the electrospun asymmetric membranes must be designed in a way that the release of the bioactive agents occurs accordingly to the wound healing stage that they will assist. Further, in the future, the incorporation of stem cells will be determinant to obtain a fully recovered skin when extensive lesions occur, e.g., regeneration of skin appendages such as hair follicles and shafts, which beyond the aesthetical role are also pivotal for the skin permeability and pigmentation. Moreover, the incorporation of multifunctional and smart materials may allow the real-time monitoring of the wound site environment (e.g., pH, redox state, inflammatory process, and infections), thus facilitating the identification and response to possible complications during the healing process. Finally, the inclusion of electrical stimulation, mechanical stress, or pulsed magnetic field may also improve the wound healing process.

Author Contributions: Conceptualization, methodology, original draft preparation, M.F.P.G.; review and editing, D.d.M.-D.; original draft preparation and review and editing, A.F.M.; review and editing, I.J.C. All authors have read and agreed to the published version of the manuscript.

Funding: This work was financed by the Foundation for Science and Technology (FCT), through funds from the State Budget, and by the European Regional Development Fund (ERDF), under the Portugal 2020 Program, through the Regional Operational Program of the Center (Centro2020), 
through the Project with the reference UIDB/00709/2020. The funding from CENTRO-01-0145FEDER-028989 and POCI-01-0145-FEDER-031462 are also acknowledged.

Data Availability Statement: No new data were created or analyzed in this study. Data sharing is not applicable to this article.

Acknowledgments: Duarte de Melo-Diogo acknowledges CENTRO-01-0145-FEDER-028989 for the funding given on the form of a research contract.

Conflicts of Interest: The funders/companies had no role in the design of the study; in the collection, analyses, or interpretation of data; in the writing of the manuscript, or in the decision to publish the results.

\section{References}

1. Guerra, A.; Belinha, J.; Jorge, R.N. Modelling skin wound healing angiogenesis: A review. J. Theor. Biol. 2018, 459, 1-17. [CrossRef]

2. Wong, R.; Geyer, S.; Weninger, W.; Guimberteau, J.-C.; Wong, J.K.F. The dynamic anatomy and patterning of skin. Exp. Dermatol. 2016, 25, 92-98. [CrossRef] [PubMed]

3. Ghomi, E.R.; Khalili, S.; Khorasani, S.N.; Neisiany, R.E.; Ramakrishna, S. Wound dressings: Current advances and future directions. J. Appl. Polym. Sci. 2019, 136, 47738. [CrossRef]

4. Pereira, R.F.; Bartolo, P.J. Traditional therapies for skin wound healing. Adv. Wound Care 2016, 5, 208-229. [CrossRef] [PubMed]

5. Dixit, S.; Baganizi, D.R.; Sahu, R.; Dosunmu, E.; A Chaudhari, A.; Vig, K.; Pillai, S.R.; Singh, S.R.; Dennis, V. Immunological challenges associated with artificial skin grafts: Available solutions and stem cells in future design of synthetic skin. J. Biol. Eng. 2017, 11, 49. [CrossRef]

6. Dreifke, M.B.; Jayasuriya, A.A.; Jayasuriya, A.C. Current wound healing procedures and potential care. Mater. Sci. Eng. C 2015, 48, 651-662. [CrossRef]

7. Haddad, A.G.; Giatsidis, G.; Orgill, D.P.; Halvorson, E.G. Skin substitutes and bioscaffolds: Temporary and permanent coverage. Clin. Plast. Surg. 2017, 44, 627-634. [CrossRef]

8. Aljghami, M.E.; Saboor, S.; Amini-Nik, S. Emerging innovative wound dressings. Ann. Biomed. Eng. 2019, 47, 659-675. [CrossRef]

9. In, S.M.; An, H.G.; Kim, J.-Y.; Lee, K.-I. Columellar Wound Immediately After Open Rhinoseptoplasty Treated With Application of DuoDERM Extra Thin. J. Craniofacial Surg. 2020, 32, e98. [CrossRef]

10. Alinejad, F.; Momeni, M.; Fatemi, M.J.; Dahmardehei, M.; Naderi, S.; Akhoondinasab, M.R.; Zayedly, M.; Mahboubi, O.; Rahbar, H. Comparing the effect of two types of silver nano-crystalline dressings (acticoat and agcoat) in the treatment of full thickness burn wound. Iran. J. Microbiol. 2018, 10, 378.

11. Kuo, F.-C.; Chen, B.; Lee, M.S.; Yen, S.-H.; Wang, J.-W. AQUACEL ${ }^{\circledR}$ Ag surgical dressing reduces surgical site infection and improves patient satisfaction in minimally invasive total knee arthroplasty: A prospective, randomized, controlled study. Biomed Res. Int. 2017, 2017, 1262108. [CrossRef] [PubMed]

12. Chen, S.; Huan, Z.; Zhang, L.; Chang, J. The clinical application of a silicate-based wound dressing (DermFactor ${ }^{\circledR}$ ) for wound healing after anal surgery: A randomized study. Int. J. Surg. 2018, 52, 229-232. [CrossRef] [PubMed]

13. Kim, H.; Makin, I.; Skiba, J.; Ho, A.; Housler, G.; Stojadinovic, A.; Izadjoo, M. Antibacterial efficacy testing of a bioelectric wound dressing against clinical wound pathogens. Open Microbiol. J. 2014, 8, 15. [CrossRef] [PubMed]

14. Simões, D.; Miguel, S.P.; Ribeiro, M.P.; Coutinho, P.; Mendonça, A.G.; Correia, I.J. European Journal of Pharmaceutics and Biopharmaceutics Recent advances on antimicrobial wound dressing: A review. Eur. J. Pharm. Biopharm. 2018, 127, 130-141. [CrossRef]

15. Dias, J.; Granja, P.; Bártolo, P. Advances in electrospun skin substitutes. Prog. Mater. Sci. 2016, 84, 314-334. [CrossRef]

16. Goodarzi, P.; Falahzadeh, K.; Nematizadeh, M.; Farazandeh, P.; Payab, M.; Larijani, B.; Beik, A.T.; Arjmand, B. Tissue engineered skin substitutes. In Cell Biology and Translational Medicine; Springer: Berlin/Heidelberg, Germany, 2018; Volume 3, pp. $143-188$.

17. Pan, C. Gas separation by permeators with high-flux asymmetric membranes. Aiche J. 1983, 29, 545-552. [CrossRef]

18. Opong, W.S.; Zydney, A.L. Diffusive and convective protein transport through asymmetric membranes. Aiche J. 1991, 37, 1497-1510. [CrossRef]

19. Zhang, D.; Patel, P.; Strauss, D.; Qian, X.; Wickramasinghe, S.R. Modeling tangential flow filtration using reverse asymmetric membranes for bioreactor harvesting. Biotechnol. Prog. 2020, e3084. [CrossRef]

20. Miguel, S.P.; Simões, D.; Moreira, A.F.; Sequeira, R.S.; Correia, I.J. Production and characterization of electrospun silk fibroin based asymmetric membranes for wound dressing applications. Int. J. Biol. Macromol. 2019, 121, 524-535. [CrossRef]

21. Norouzi, M.; Boroujeni, S.M.; Omidvarkordshouli, N.; Soleimani, M. Advances in skin regeneration: Application of electrospun scaffolds. Adv. Healthc. Mater. 2015, 4, 1114-1133. [CrossRef]

22. Miguel, S.P.; Moreira, A.F.; Correia, I.J. Chitosan based-asymmetric membranes for wound healing: A review. Int. J. Biol. Macromol. 2019, 127, 460-475. [CrossRef] [PubMed]

23. Morgado, P.I.; Lisboa, P.F.; Ribeiro, M.P.; Miguel, S.P.; Simões, P.C.; Correia, I.J.; Aguiar-Ricardo, A. Poly (vinyl alcohol)/chitosan asymmetrical membranes: Highly controlled morphology toward the ideal wound dressing. J. Membr. Sci. 2014, 469, $262-271$. [CrossRef] 
24. Wang, J.; Windbergs, M. Functional electrospun fibers for the treatment of human skin wounds. Eur. J. Pharm. Biopharm. 2017, 119, 283-299. [CrossRef] [PubMed]

25. Das, S.; Baker, A.B. Biomaterials and nanotherapeutics for enhancing skin wound healing. Front. Bioeng. Biotechnol. 2016, 4, 82. [CrossRef]

26. Chanda, A.; Adhikari, J.; Ghosh, A.; Chowdhury, S.R.; Thomas, S.; Datta, P.; Saha, P. Electrospun chitosan/polycaprolactonehyaluronic acid bilayered scaffold for potential wound healing applications. Int. J. Biol. Macromol. 2018, 116, 774-785. [CrossRef]

27. Franco, R.A.; Min, Y.-K.; Yang, H.-M.; Lee, B.-T. Fabrication and biocompatibility of novel bilayer scaffold for skin tissue engineering applications. J. Biomater. Appl. 2013, 27, 605-615. [CrossRef]

28. Figueira, D.R.; Miguel, S.P.; De Sá, K.D.; Correia, I.J. Production and characterization of polycaprolactone-hyaluronic acid/chitosan-zein electrospun bilayer nanofibrous membrane for tissue regeneration. Int. J. Biol. Macromol. 2016, 93, 1100-1110. [CrossRef]

29. Morgado, P.I.; Aguiar-Ricardo, A.; Correia, I.J. Asymmetric membranes as ideal wound dressings: An overview on production methods, structure, properties and performance relationship. J. Membr. Sci. 2015, 490, 139-151. [CrossRef]

30. Hinrichs, W.; Lommen, E.J.C.M.P.; Wildevuur, C.R.H.; Feijen, J. Fabrication and characterization of an asymmetric polyurethane membrane for use as a wound dressing. J. Appl. Biomater. 1992, 3, 287-303. [CrossRef]

31. Mousavi, S.M.; Zarei, M.; Hashemi, S.A.; Ramakrishna, S.; Chiang, W.-H.; Lai, C.W.; Gholami, A.; Omidifar, N.; Shokripour, M. Asymmetric Membranes: A Potential Scaffold for Wound Healing Applications. Symmetry 2020, 12, 1100. [CrossRef]

32. Marcano, A.; Haidar, N.B.; MaraisOrcid, S.; Valleton, J.-M.; Duncan, A.C. Designing biodegradable PHA-based 3D scaffolds with antibiofilm properties for wound dressings: Optimization of the microstructure/nanostructure. Acs Biomater. Sci. Eng. 2017, 3, 3654-3661. [CrossRef] [PubMed]

33. Sun, A.C.; Kosar, W.; Zhang, Y.; Feng, X. A study of thermodynamics and kinetics pertinent to formation of PVDF membranes by phase inversion. Desalination 2013, 309, 156-164. [CrossRef]

34. Mi, F.-L.; Wu, Y.-B.; Shyu, S.-S.; Chao, A.-C.; Lai, J.-Y.; Su, C.-C. Asymmetric chitosan membranes prepared by dry/wet phase separation: A new type of wound dressing for controlled antibacterial release. J. Membr. Sci. 2003, 212, 237-254. [CrossRef]

35. Cardea, S.; Sessa, M.; Reverchon, E. Supercritical phase inversion to form drug-loaded poly (vinylidene fluoride-cohexafluoropropylene) membranes. Ind. Eng. Chem. Res. 2010, 49, 2783-2789. [CrossRef]

36. Temtem, M.; Casimiro, T.; Aguiar-Ricardo, A. Solvent power and depressurization rate effects in the formation of polysulfone membranes with CO2-assisted phase inversion method. J. Membr. Sci. 2006, 283, 244-252. [CrossRef]

37. Morgado, P.I.; Miguel, S.P.; Correia, I.J.; Aguiar-Ricardo, A. Ibuprofen loaded PVA/chitosan membranes: A highly efficient strategy towards an improved skin wound healing. Carbohydr. Polym. 2017, 159, 136-145. [CrossRef]

38. Rogina, A. Electrospinning process: Versatile preparation method for biodegradable and natural polymers and biocomposite systems applied in tissue engineering and drug delivery. Appl. Surf. Sci. 2014, 296, 221-230. [CrossRef]

39. Park, S.; Park, K.; Yoon, H.; Son, J.; Min, T.; Kim, G. Apparatus for preparing electrospun nanofibers: Designing an electrospinning process for nanofiber fabrication. Polym. Int. 2007, 56, 1361-1366. [CrossRef]

40. Bombin, A.D.J.; Dunne, N.; McCarthy, H.O. Electrospinning of natural polymers for the production of nanofibres for wound healing applications. Mater. Sci. Eng. C 2020, 114, 110994. [CrossRef]

41. Haider, A.; Haider, S.; Kang, I.-K. A comprehensive review summarizing the effect of electrospinning parameters and potential applications of nanofibers in biomedical and biotechnology. Arab. J. Chem. 2018, 11, 1165-1188. [CrossRef]

42. Felgueiras, H.P.; Amorim, M.T.P. Functionalization of electrospun polymeric wound dressings with antimicrobial peptides. Colloids Surf. B Biointerfaces 2017, 156, 133-148. [CrossRef] [PubMed]

43. Miguel, S.P.; Figueira, D.R.; Simões, D.; Ribeiro, M.P.; Coutinho, P.; Ferreira, P.; Correia, I.J. Electrospun polymeric nanofibres as wound dressings: A review. Colloids Surf. B Biointerfaces 2018, 169, 60-71. [CrossRef] [PubMed]

44. Jayasinghe, S.N. Cell electrospinning: A novel tool for functionalising fibres, scaffolds and membranes with living cells and other advanced materials for regenerative biology and medicine. Analyst 2013, 138, 2215-2223. [CrossRef] [PubMed]

45. Chen, H.; Liu, Y.; Hu, Q. A novel bioactive membrane by cell electrospinning. Exp. Cell Res. 2015, 338, 261-266. [CrossRef] [PubMed]

46. Guo, Y.; Gilbert-Honick, J.; Somers, S.M.; Mao, H.-Q.; Grayson, W. Modified cell-electrospinning for 3D myogenesis of C2C12s in aligned fibrin microfiber bundles. Biochem. Biophys. Res. Commun. 2019, 516, 558-564. [CrossRef]

47. Ang, H.Y.; Irvine, S.A.; Avrahami, R.; Sarig, U.; Bronshtein, T.; Zussman, E.; Boey, F.Y.C.; Machluf, M.; Venkatraman, S.S. Characterization of a bioactive fiber scaffold with entrapped HUVECs in coaxial electrospun core-shell fiber. Biomatter 2014, 4, e28238. [CrossRef]

48. De Prá, M.A.A.; Ribeiro-do-Valle, R.M.; Maraschin, M.; Veleirinho, B. Effect of collector design on the morphological properties of polycaprolactone electrospun fibers. Mater. Lett. 2017, 193, 154-157. [CrossRef]

49. Sequeira, R.S.; Miguel, S.P.; Cabral, C.S.; Moreira, A.F.; Ferreira, P.; Correia, I.J. Development of a poly (vinyl alcohol)/lysine electrospun membrane-based drug delivery system for improved skin regeneration. Int. J. Pharm. 2019, 570, 118640. [CrossRef]

50. Abrigo, M.; McArthur, S.L.; Kingshott, P. Electrospun nanofibers as dressings for chronic wound care: Advances, challenges, and future prospects. Macromol. Biosci. 2014, 14, 772-792. [CrossRef]

51. Chen, S.; Li, R.; Li, X.; Xie, J. Electrospinning: An enabling nanotechnology platform for drug delivery and regenerative medicine. Adv. Drug Deliv. Rev. 2018, 132, 188-213. [CrossRef] 
52. Zhang, Q.; Li, Y.; Lin, Z.Y.; Wong, K.K.Y.; Lin, M.; Yildirimer, L.; Zhao, X. Electrospun polymeric micro/nanofibrous scaffolds for long-term drug release and their biomedical applications. Drug Discov. Today 2017, 22, 1351-1366. [CrossRef] [PubMed]

53. Reshmi, C.; Menon, T.; Binoy, A.; Mishra, N.; Elyas, K.K.; Sujith, A. Poly (L-lactide-co-caprolactone)/collagen electrospun mat: Potential for wound dressing and controlled drug delivery. Int. J. Polym. Mater. Polym. Biomater. 2017, 66, 645-657. [CrossRef]

54. Yu, B.; He, C.; Wang, W.; Ren, Y.; Yang, J.; Guo, S.; Zheng, Y.; Shi, X. Asymmetric Wettable Composite Wound Dressing Prepared by Electrospinning with Bioinspired Micropatterning Enhances Diabetic Wound Healing. ACS Appl. Bio Mater. 2020, 3, 5383-5394. [CrossRef]

55. Alves, P.; Santos, M.; Mendes, S.; Miguel, S.P.; De Sá, K.D.; Cabral, C.S.D.; Correia, I.J.; Ferreira, P. Photocrosslinkable nanofibrous asymmetric membrane designed for wound dressing. Polymers 2019, 11, 653. [CrossRef] [PubMed]

56. Buck, E.; Maisuria, V.; Tufenkji, N.; Cerruti, M. Antibacterial Properties of PLGA Electrospun Scaffolds Containing Ciprofloxacin Incorporated by Blending or Physisorption. Acs Appl. Bio Mater. 2018, 1, 627-635. [CrossRef]

57. Zahid, S.; Khalid, H.; Ikram, F.; Iqbal, H.; Samie, M.; Shahzadi, L.; Shah, A.T.; Yar, M.; Chaudhry, A.A.; Awan, S.J.; et al. Bi-layered $\alpha$-tocopherol acetate loaded membranes for potential wound healing and skin regeneration. Mater. Sci. Eng. C 2019, 101, 438-447. [CrossRef]

58. Liang, D.; Hsiao, B.S.; Chu, B. Functional electrospun nanofibrous scaffolds for biomedical applications. Adv. Drug Deliv. Rev. 2007, 59, 1392-1412. [CrossRef] [PubMed]

59. Oliveira, S.M.; Alves, N.M.; Mano, J.F. Cell interactions with superhydrophilic and superhydrophobic surfaces. J. Adhes. Sci. Technol. 2014, 28, 843-863. [CrossRef]

60. Mele, E. Electrospinning of natural polymers for advanced wound care: Towards responsive and adaptive dressings. J. Mater. Chem. B 2016, 4, 4801-4812. [CrossRef]

61. Wu, C.; Chen, T.; Xin, Y.; Zhang, Z.; Ren, Z.; Lei, J.; Chu, B.; Wang, Y.; Tang, S. Nanofibrous asymmetric membranes self-organized from chemically heterogeneous electrospun mats for skin tissue engineering. Biomed. Mater. 2016, 11, 035019. [CrossRef]

62. Jeckson, T.A.; Neo, Y.P.; Sisinthy, S.P.; Gorain, B. Delivery of therapeutics from layer-by-layer electrospun nanofiber matrix for wound healing: An update. J. Pharm. Sci. 2020, 110, 635-653. [CrossRef] [PubMed]

63. Liu, Y.; Zhou, S.; Gao, Y.; Zhai, Y. Electrospun nanofibers as a wound dressing for treating diabetic foot ulcer. Asian J. Pharm. Sci. 2019, 14, 130-143. [CrossRef]

64. Chen, S.-H.; Chang, Y.; Lee, K.; Lai, J.-Y. A three-dimensional dual-layer nano/microfibrous structure of electrospun chitosan/poly (d, l-lactide) membrane for the improvement of cytocompatibility. J. Membr. Sci. 2014, 450, 224-234. [CrossRef]

65. Dodero, A.; Alloisio, M.; Castellano, M.; Vicini, S. Multilayer Alginate-Polycaprolactone Electrospun Membranes as Skin Wound Patches with Drug Delivery Abilities. ACS Appl. Mater. Interfaces 2020, 12, 31162-31171. [CrossRef] [PubMed]

66. Aragón, J.; Costa, C.; Coelhoso, I.; Mendoza, G.; Aguiar-Ricardo, A.; Irusta, S. Electrospun asymmetric membranes for wound dressing applications. Mater. Sci. Eng. C 2019, 103, 109822. [CrossRef]

67. Miguel, S.P.; Ribeiro, M.P.; Coutinho, P.; Correia, I.J. Electrospun polycaprolactone/aloe vera_chitosan nanofibrous asymmetric membranes aimed for wound healing applications. Polymers 2017, 9, 183. [CrossRef]

68. Li, X.; Wang, C.; Yang, S.; Liu, P.; Zhang, B. Electrospun PCL/mupirocin and chitosan/lidocaine hydrochloride multifunctional double layer nanofibrous scaffolds for wound dressing applications. Int. J. Nanomed. 2018, 13, 5287. [CrossRef]

69. Rezk, A.I.; Lee, J.Y.; Son, B.C.; Park, C.H.; Kim, C.S. Bi-layered Nanofibers Membrane Loaded with Titanium Oxide and Tetracycline as Controlled Drug Delivery System for Wound Dressing Applications. Polymers 2019, 11, 1602. [CrossRef]

70. Amini, F.; Semnani, D.; Karbasi, S.; Banitaba, S.N. A novel bilayer drug-loaded wound dressing of PVDF and PHB/Chitosan nanofibers applicable for post-surgical ulcers. Int. J. Polym. Mater. Polym. Biomater. 2019, 68, 772-777. [CrossRef]

71. Zhao, R.; Li, X.; Sun, B.; Tong, Y.; Jiang, Z.; Wang, C. Nitrofurazone-loaded electrospun PLLA/sericin-based dual-layer fiber mats for wound dressing applications. RSC Adv. 2015, 5, 16940-16949. [CrossRef]

72. Balusamy, B.; Celebioglu, A.; Senthamizhan, A.; Uyar, T. Progress in the design and development of "fast-dissolving" electrospun nanofibers based drug delivery systems-A systematic review. J. Control. Release 2020, 326, 482-509. [CrossRef] [PubMed]

73. Yang, G.; Li, X.; He, Y.; Ma, J.; Ni, G.; Zhou, S. From nano to micro to macro: Electrospun hierarchically structured polymeric fibers for biomedical applications. Prog. Polym. Sci. 2018, 81, 80-113. [CrossRef]

74. Khalf, A.; Madihally, S.V. Recent advances in multiaxial electrospinning for drug delivery. Eur. J. Pharm. Biopharm. 2017, 112, 1-17. [CrossRef] [PubMed]

75. Cheng, H.; Yang, X.; Che, X.; Yang, M.; Zhai, G. Biomedical application and controlled drug release of electrospun fibrous materials. Mater. Sci. Eng. C 2018, 90, 750-763. [CrossRef] [PubMed]

76. Kamble, P.; Sadarani, B.; Majumdar, A.; Bhullar, S. Nanofiber based drug delivery systems for skin: A promising therapeutic approach. J. Drug Deliv. Sci. Technol. 2017, 41, 124-133. [CrossRef]

77. Wang, W.; Zhou, S.; Liu, Z.; Yang, W.; Lin, Y.; Qian, H.; Gao, F.; Li, G. Investigation on the structural properties of GaN films grown on La0. 3Sr1. 7AlTaO6 substrates. Mater. Res. Express 2014, 1, 025903. [CrossRef]

78. Pant, B.; Park, M.; Park, S.-J. Drug delivery applications of core-sheath nanofibers prepared by coaxial electrospinning: A review. Pharmaceutics 2019, 11, 305. [CrossRef]

79. Li, L.; Yang, G.; Zhou, G.; Yi, W.; Zheng, X.; Zhou, S. Thermally switched release from a Nanogel-in-microfiber device. Adv. Healthc. Mater. 2015, 4, 1658-1663. [CrossRef] 
80. Yohe, S.T.; Kopechek, J.A.; Porter, T.M.; Colson, Y.L.; Grinstaff, M. Triggered drug release from Superhydrophobic meshes using high-intensity focused ultrasound. Adv. Healthc. Mater. 2013, 2, 1204-1208. [CrossRef]

81. Sun, J.; Song, L.; Fan, Y.; Tian, L.; Luan, S.; Niu, S.; Ren, L.; Ming, W.; Zhao, J. Synergistic photodynamic and photothermal antibacterial nanocomposite membrane triggered by single NIR light source. ACS Appl. Mater. Interfaces 2019, 11, 26581-26589. [CrossRef]

82. Miguel, S.P.; Ribeiro, M.P.; Brancal, H.; Coutinho, P.; Correia, I.J. Thermoresponsive chitosan-agarose hydrogel for skin regeneration. Carbohydr. Polym. 2014, 111, 366-373. [CrossRef] [PubMed]

83. Aavani, F.; Khorshidi, S.; Karkhaneh, A. A concise review on drug-loaded electrospun nanofibres as promising wound dressings. J. Med. Eng. Technol. 2019, 43, 38-47. [CrossRef] [PubMed]

84. Jin, G.; Prabhakaran, M.P.; Kai, D.; Ramakrishna, S. Controlled release of multiple epidermal induction factors through core-shell nanofibers for skin regeneration. Eur. J. Pharm. Biopharm. 2013, 85, 689-698. [CrossRef] [PubMed]

85. Miguel, S.P.; Sequeira, R.S.; Moreira, A.F.; Cabral, C.S.; Mendonça, A.G.; Ferreira, P.; Correia, I.J. An overview of electrospun membranes loaded with bioactive molecules for improving the wound healing process. Eur. J. Pharm. Biopharm. 2019, 139, 1-22. [CrossRef] [PubMed]

86. Thakkar, S.; Misra, M. Electrospun polymeric nanofibers: New horizons in drug delivery. Eur. J. Pharm. Sci. 2017, 107, 148-167. [CrossRef]

87. Hu, X.; Liu, S.; Zhou, G.; Huang, Y.; Xie, Z.; Jing, X. Electrospinning of polymeric nanofibers for drug delivery applications. J. Control. Release 2014, 185, 12-21. [CrossRef]

88. Boateng, J.S.; Matthews, K.H.; Stevens, H.N.; Eccleston, G.M. Wound healing dressings and drug delivery systems: A review. J. Pharm. Sci. 2008, 97, 2892-2923. [CrossRef]

89. Palmieri, B.; Vadalà, M.; Laurino, C. Nutrition in wound healing: Investigation of the molecular mechanisms, a narrative review. J. Wound Care 2019, 28, 683-693. [CrossRef]

90. Ranjith, R.; Balraj, S.; Ganesh, J.; Milton, M.J. Therapeutic agents loaded chitosan-based nanofibrous mats as potential wound dressings: A review. Mater. Today Chem. 2019, 12, 386-395. [CrossRef] 